\title{
Chefs' Perspectives of Failures in Foodservice Kitchens, Part 1: A phenomenological exploration of the concepts, types, and causes of food production failure
}

\author{
Máirtín Mac Con lomaire \\ Technological University Dublin, mairtin.macconiomaire@tudublin.ie \\ JJ Healy \\ Cork Institute of Technology, JJ.Healy@cit.ie \\ Mohamed Fawzi Afiffi \\ University of Sadat City, Sadat City, Egypt, mf.afifi@fth.usc.edu.eg
}

Follow this and additional works at: https://arrow.tudublin.ie/tfschafart

Part of the Food Studies Commons

\section{Recommended Citation 15378020.2020 .1842955 \\ This Article is brought to you for free and open access by the School of Culinary Arts and Food Technology at ARROW@TU Dublin. It has been accepted for inclusion in Articles by an authorized administrator of ARROW@TU Dublin. For more information, please contact arrow.admin@tudublin.ie, aisling.coyne@tudublin.ie, gerard.connolly@tudublin.ie.}

Mac Con lomaire, M., Fawzi Afifi, M. \& Healy, J.J. (2020). Chefs' perspectives of failures in foodservice kitchens, part 1: A phenomenological exploration of the concepts, types, and causes of food production failure. Journal of Foodservice Business Research, vol. 24, no. 2, pg. 177-214. DOI: 10.1080/

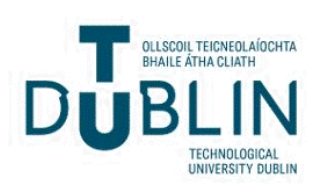




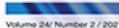

\title{
Chefs' perspectives of failures in foodservice kitchens, part 1: A phenomenological exploration of the concepts, types, and causes of food production failure
}

\author{
Máirtín Mac Con lomaire, Mohamed Fawzi Afifi \& JJ Healy
}

To cite this article: Máirtín Mac Con lomaire, Mohamed Fawzi Afifi \& JJ Healy (2021) Chefs' perspectives of failures in foodservice kitchens, part 1: A phenomenological exploration of the concepts, types, and causes of food production failure, Journal of Foodservice Business Research, 24:2, 177-214, DOI: $10.1080 / 15378020.2020 .1842955$

To link to this article: https://doi.org/10.1080/15378020.2020.1842955

曲 Published online: 20 Nov 2020.

Submit your article to this journal $\pi$

Џll Article views: 442

Q View related articles 둔

View Crossmark data ־

Citing articles: 1 View citing articles ¿ð 


\title{
Chefs' perspectives of failures in foodservice kitchens, part 1: A phenomenological exploration of the concepts, types, and causes of food production failure
}

\author{
Máirtín Mac Con lomaire (D) ${ }^{a}$, Mohamed Fawzi Afifi (D) $^{b}$, and JJ Healy (D) ${ }^{c}$ \\ ${ }^{a}$ College of Arts and Tourism, Technological University Dublin (City Campus), Dublin, Ireland; \\ bDepartment of Hotel Studies, Faculty of Tourism and Hotels, University of Sadat City, Sadat City, Egypt; \\ 'Department of Tourism and Hospitality, Cork Institute of Technology, Cork, Ireland
}

\begin{abstract}
The purpose of this paper is to explore the concept, types, and causes of food production failure (FPF) in restaurant kitchens from the perspective of chefs. Employing a phenomenological epistemology, a qualitative methodology was adopted to explore FPF. Extant literature was reviewed. Using purposive sampling, and employing an emic posture, 15 semi-structured interviews were conducted with senior restaurant and hotel chefs until saturation occurred. Interviews were transcribed, read repeatedly, and coded using the qualitative analysis software package QDA Miner Lite. An inter-rater reliability score of .78 using Cohen's Kappa coefficient formula reflected substantial agreement between coders. Thematic analysis was used. The study revealed three main categories of FPF types (sensory/organoleptic, safety, other) and FPF causes (People related failure; Operation-related failure; and Food supply/ supplier-related failures). A conceptual model was developed from these categories underpinned by management control systems, continuous training, clear communication, and the organizational culture and climate of kitchens. Chefs found that FPF was inevitable based on human error, and can be precipitated by certain factors but reduced by other interventions. Research findings may assist in reducing its frequency, thereby increasing customer satisfaction and retention while reducing financial and environmental costs of FPF. Practical, theoretical, and managerial implications are discussed.
\end{abstract}

\section{KEYWORDS}

Food production failure; restaurants; chefs; phenomenology; practice theory

CONTACT Máirtín Mac Con lomaire mairtin.macconiomaire@tudublin.ie $\Theta$ College of Arts and Tourism, Technological University Dublin (City Campus), Dublin, Ireland 


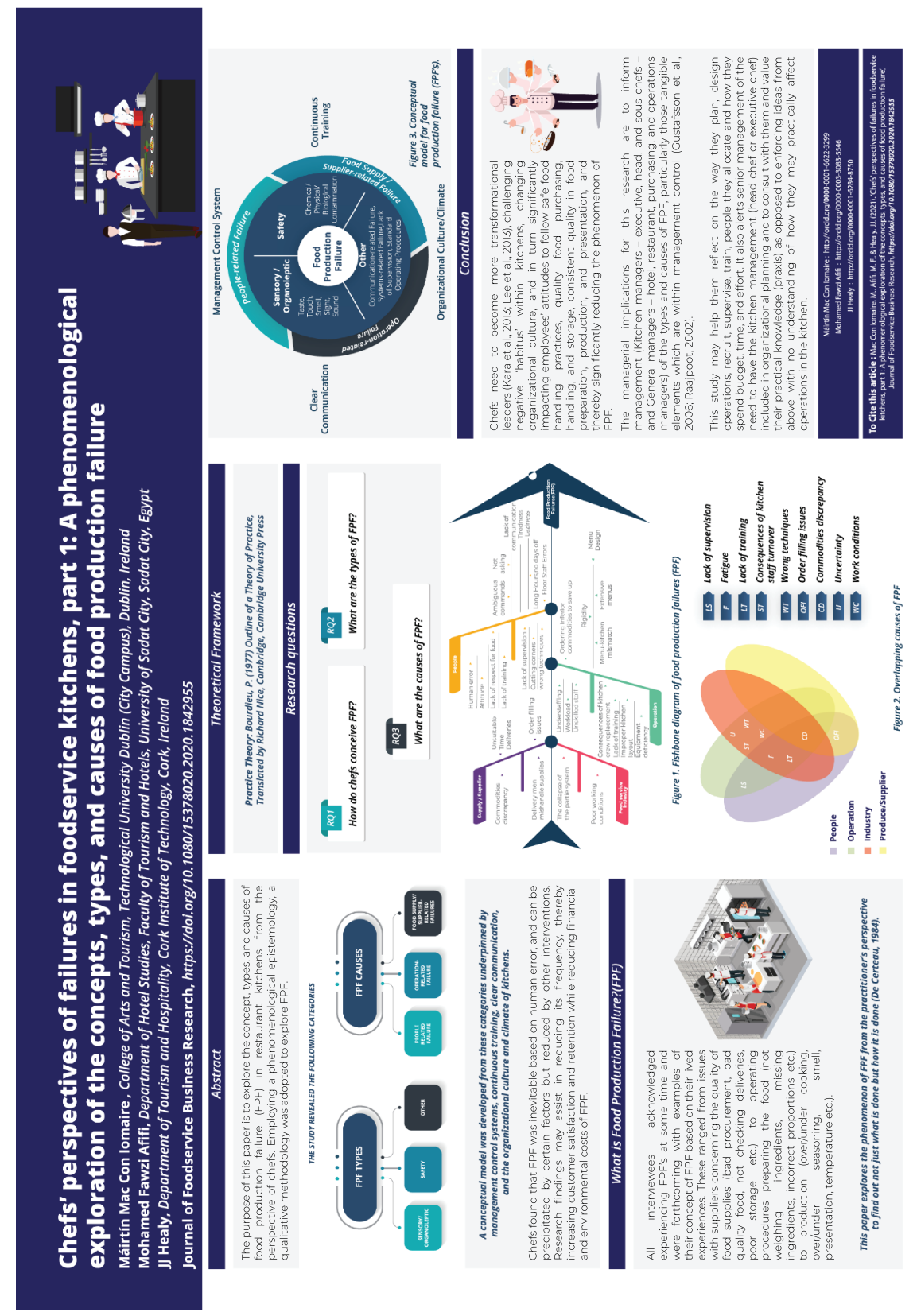




\section{Introduction}

Customers visit restaurants for varying reasons ranging from utilitarian - to satisfy hunger - to hedonistic - displaying cultural capital (Bourdieu, 1984) more recently theorized as culinary capital (Naccarato \& Lebesco, 2012). Restaurants are even more significant in the new 'experience economy' (Pine \& Gilmore, 1998) where lunch or dinner are conceptualized as 'meal experiences.' There is widespread acceptance of the pivotal role (about 33\% of tourist spend) that food now plays in the tourism product of any country (Quigley et al., 2019). Food quality is consistently identified as among the most important factors of the restaurant experience and has substantial influence on consumer satisfaction (Auty, 1992; Clark \& Wood, 1998; Kivela et al., 1999; Namkung \& Jang, 2007, 2008; Oh, 2000; Pantelidis, 2010; Raajpoot, 2002; Ramdeen et al., 2007; Sulek \& Hensley, 2004; Susskind \& Chan, 2000). Customer satisfaction is a crucial target in maximizing restaurant revenue (Gupta et al., 2007; Susskind, 2002). Satisfied customers are more likely to become repeat customers and to recommend the restaurant through positive word of mouth, also known as viral marketing, particularly important in today's world of social media and online restaurant rating platforms (Bilghian et al., 2014; DiPietro et al., 2012; Lepkowska-White \& Parsons, 2019; Longart, 2010; Pantelidis, 2010). Repeat customers were also found to spend more on food and beverage (Ramdeen et al., 2007). Dissatisfied customers are significantly more likely to inform other people of their dining experiences than satisfied customers (Susskind, 2002) and the majority of them never return (Sulek \& Hensley, 2004).

Despite the importance of food within the meal experience, many kitchens fail to produce quality food (Ozdemir et al., 2015; Silber et al., 2009), which is referred to in this paper as 'food production failure' (FPF). Producing consistent quality food is central to the success of any restaurant. Improved understanding of the types and causes of FPF may assist in the training of chefs and hospitality managers to avoid repeating common errors, and reduce the financial cost of quality (Ramdeen et al., 2007). This in turn might also help reduce food waste, which is a particular topical issue in the Anthropocene (DiPietro et al., 2013; Filimonau et al., 2020; Okumus, 2020; Silvennoinen et al., 2015).

There has been growing interest for decades in critical success factors for restaurants and the question of why restaurants fail (Healy \& Mac Con Iomaire, 2019; Parsa et al., 2005; Self et al., 2015). Service failure has also been widely researched within the service management and marketing literature (Chung \& Hoffman, 1998; Lewis \& McCann, 2004; Loo et al., 2013; Namkung \& Jang, 2010; Silber et al., 2009). However, Chan et al. (2014, p. 223) assert that while previous studies have extensively looked into the facet of service in the restaurant setting, they have left "the product aspect largely unaddressed." Food is produced in professional kitchens which are historically hierarchical work environments, organized around the 'partie system' which stems from authoritarian military 
origins (Cooper et al., 2017; Giousmpasoglou et al., 2018). The occupational culture of chefs is strong and often differs from the organizational culture of the particular workplace, a phenomenon which remains under researched (Allen \& Mac Con Iomaire, 2016; Cooper et al., 2017; Giousmpasoglou et al., 2018; Zopiatis, 2010). Kitchen brigades are frequently forced to work at peak performance while understaffed and using broken equipment (Mac Con Iomaire, 2008), a practice that would not be tolerated in many other occupations.

Following the practice turn in sociology (Kalogeropoulos et al., 2020; Schatzki, 2018), practice theory which incorporates Bourdieu's theory of practice assists in understanding how things are done "know how" and not just what is done "know that." This phenomenological paper explores chefs' "lived experience" of FPF within their "praxis" and "habitus." The concepts of "praxis," "habitus," "field", and "capital" from Bourdieu's theoretical toolbox have previously been of value in analyzing restaurants, kitchens, and chefs (Ferguson, 1998; Mennell, 1996; Fantasia, 2018). Research on food quality in restaurants, theorized as food production failure (FPF) in this paper, has long been identified as lacking in the academic literature (Andaleeb \& Conway, 2006; Chan et al., 2014; Cousins et al., 2002; Gadelrab, 2010; Jones \& Lockwood, 2004). A systematic search of the literature using Web of Science, Google Scholar, and Scopus databases using the keywords 'food,' 'quality,' 'failure,' restaurant,' 'chef confirm the gap in the literature still exists. This phenomenological qualitative research begins to address this lacuna by exploring the lived experiences of executive and head chefs in both independent and hotel restaurants in the Republic of Ireland concerning the concepts, types, and causes of FPF. It is anticipated that the rich descriptive findings and conceptual model of FPF developed in this paper will be of value to a number of different stakeholders within the hospitality industry.

\section{Review of literature}

A systematic review of the literature failed to uncover any specific peerreviewed journal article concerning food production failure (FPF) and why kitchens fail. While a "steady trickle of literature" has explored issues concerning the occupation of professional cookery in the last 30 years (Robinson \& Barron, 2007) and that trickle has grown into a steadier stream in the intervening decade, much of the available printed material on elements of FPF appears in hospitality or culinary textbooks (Cousins et al., 2002; Feinstein \& Stefanelli, 2012; Jones \& Lockwood, 2004; Katsigris \& Thomas, 2009) or in the gray literature - printed or electronic reports or thesis from government, academics, business, or industry not controlled by commercial publishers (Chivers, 1972; Gadelrab, 2010). The review below provides 
a conceptual and theoretical overview of the world of professional kitchens in order to better understand the phenomenon of FPF.

\section{Kitchen culture}

Kitchens seem inherently as tough places to work (Balazs, 2002; James, 2006; Meloury \& Signal, 2014; Pratten, 2003). They are portrayed more like a battlefield, with the term 'kitchen brigade' stemming from the military (James, 2006; Mac Con Iomaire, 2008; Fantasia, 2018). As previously outlined, research on chefs and kitchen staff is historically underrepresented in the hospitality literature (Allen \& Mac Con Iomaire, 2016; Zopiatis, 2010). Early sociological research on chefs was conducted in Chicago (Whyte, 1948), the UK (Chivers, 1972), and later in Minnesota (Fine, 1996) where the occupational rhetoric of chefs' work ranged from that of artist to manual laborer. The occupational identity of chefs historically has included many metaphors: professional, CEO, businessman, craftsperson, scientist, humanist, and philosopher (Fine, 1996; Mac Con Iomaire, 2015; Mac Con Iomaire, 2013; Mennell, 1996). Indeed, Zopiatis (2010) reinforces the debate when asking whether chefs are scientists or artists. As previously stated, the occupational identity of chefs can differ from the organizational culture of the business.

Chefs work in stressful settings and they are required to make no mistakes (Meloury \& Signal, 2014; Zopiatis et al., 2011), although it is widely accepted that errors are a factor of the hospitality industry (Yao et al., 2019). One way to vent their tension and stress is through drinking (Borchgrevink et al., 1998), shouting, and hard jokes (James, 2006). Aggression and bullying are not uncommon (Cooper et al., 2017; Giousmpasoglou et al., 2018; Meloury \& Signal, 2014). Verbal abuse is not unusual in the culture of kitchens (Gill \& Burrow, 2018; Murray-Gibbons \& Gibbons, 2007). Abusive supervision may provoke employees to engage in counterproductive behaviors and retraction of helpful behaviors (Zhao \& Guo, 2019), a phenomenon that can be explained using both equity theory and social exchange theory (Yao et al., 2019). Furthermore, kitchens seem a masculinized territory, described as possessing a "reputation for sexism" (Pratten, 2003, p. 455). Awareness and discussion of gender inequality in professional kitchens in both academic literature and the media is growing (Albors-Garrigos et al., 2020; Harris \& Giuffre, 2015).

Fear is another emotion associated with kitchens and it comes in many forms. Initially, there is fear of making mistakes and the consequences of these, which is labeled by Gill and Burrow (2018) as "practice fear." Another type of fear is "professional fear" which is "the fear of not being proficient or "good enough' across a range of complex culinary skills to ensure continued employment" (Gill \& Burrow, 2018, p. 451). Fear in kitchens has been studied and it was regarded as an essential element of work (Gill \& Burrow, 2018). Actually, chefs interviewed by Gill and Burrow (2018, p. 455) viewed fear as " ... the 
optimum way to galvanize and focus effort." Moreover, fear was believed to be the way to ensure not incurring failure again. An alternative approach to fear would be the concept of error management, a supplementary tactic to error prevention (Frese \& Keith, 2015). Indeed, error management training (EMT) sees that errors can be an integral part of training as "a natural by-product of active learning" (Yao et al., 2019, p. 79). However, EMT is not widespread in the restaurant industry and negative emotions associated with fear can lead to stress. Occupational stress, however, can lead to burn out and increased intention to leave (Murray-Gibbons \& Gibbons, 2007). However, it is not all bad news. Some chefs enjoy this intense, nerve-breaking atmosphere (Borchgrevink et al., 1998; Eburne, 2010). They find excitement in this bustling setting, as Chef Daniel Boulud (cited from Eburne, 2010, p. 173) elaborates:

\begin{abstract}
Although I will never deny that it is hard work to become a chef, the clatter of the kitchen, the intense aromas, the mix of languages, the precision teamwork of the kitchen brigade when the service is really rocking ... all of these things make me feel alive and charged in a way that nothing else can.
\end{abstract}

\title{
Classification of restaurants
}

Hospitality outlets supplying food and drink range in size from self-employed street vendors to multi-international restaurant chains, like McDonalds (Taylor \& Forte, 2008). Occupational culture among chefs differs across the hospitality sectors (Robinson \& Barron, 2007), with major differences historically shown, for example, between hospital and hotel chefs (Chivers, 1972). Fine dining or Michelin-star restaurants have been shown to have their own particular culture (Balazs, 2002; Cooper et al., 2017; Giousmpasoglou et al., 2018). Canziani et al. (2016) note the importance of classifying restaurants to improve usability of restaurant research to boost internal and external validity of research findings. Parsa et al. (2020) provide a theoretically supported restaurant classification system for the US based on the concept of hedonic and utilitarian consumption, proposing four major classes: Luxury Restaurants, Fine-Dining Restaurants, Casual Restaurants, and QuickService Restaurants.

Cameron (2001) studied the effect restructuring the Forte Group PLC in the UK in the mid-1990s had on the occupational culture of chefs within their properties using the grid-group analysis model developed by Mars and Nicod (1984), who identified four typologies (1) Entrepreneurial Hotels (2) Craft Hotels (3) Bureaucratic Hotels, and (4) Traditional Hotels (Mars \& Nicod, 1984, pp. 126-7). Cameron (2001) identifies that not all hotel restaurants are the same, for example, the quality of food served in a Craft Hotel would be superior to a Traditional Hotel. Working in hotel restaurants is also different from working in independent ones. Chef Jennifer Carrol as interviewed by 
Cimimin (2011, p. 34) stated that moving from independent restaurants to a hotel restaurant was a "culture shock." Working in a hotel provides a substantial support in many areas that may not be readily available to standalone operations, in areas such as maintenance and purchasing (Cimimin, 2011). Furthermore, autonomy afforded by independent restaurants is lost as the hotel chef becomes a gear in the big machine. Many chain restaurants, particularly fast food, or quick-service, and indeed some bureaucratic hotels have such tight standard operating procedures (SOPs) that no autonomy or room for creativity is left for the workers, who are often considered line cooks rather than chefs (Reiter, 1996; Rodgers, 2008). This can lead to apathy and influence turnover intention as further discussed below.

\section{Production cycle of restaurant kitchens and quality systems}

Professional kitchens are like many other production sites with cycles of inputs, processes, and outputs. However, they differ from normal manufacturing in that there are far more variables (fluctuation and uncertainty of demand, shortages of staff and equipment, and frequent menu changes). Taylor (2008) argued that hospitality as a service industry, serving food direct to the end-consumer, often requires high levels of flexibility to meet the unpredictable and continually changing demands of the customer and the needs of the business. The intangibility, heterogeneity, inseparability, and perishability of hospitality offerings result in continuously improving being a more complex and subjective process than its manufacturing equivalent (Farrington et al., 2018).

Work in kitchens requires a high degree of cooperation and synchronization among the different sections and the different chefs working within these (James, 2006). Most items are the product of different hands and sections. James (2006, p. 13) notes "the flow of work revolves around the dish rather than the workers." The chef working in close collaboration with the waiter is the end producer of the 'meal experience' for human pleasure and enjoyment. Hegarty (2008, p. 1) argues that the meal involves "the science of selection and combination, the technology of preparation and processing (including the techniques of cooking), the esthetic/artistic experiences of design, presentation, and service in an environment conducive to the integration of these experiences into providing social meaning." Rozin (1982, p. 191) defines "cooking" in its widest sense, to cover "any and all culinary manipulations performed to alter a foodstuff in some predictable fashion" and not merely applying heat to food. Quality food production begins with quality food selection and supply. Murphy and Smith (2009, p. 213) note that "... [w]ith respect to restaurants, a properly managed supply chain also supports the chef's ability to build relationships with suppliers, identify new sources, and manage supplier relationships.” 
Some of the quality management systems used in food production to provide products of consistent quality include Total Quality Management (TQM) and the ISO standard, but their manufacturing origins made them too complicated to be generally applied in service industries, such as restaurants and hotel operations, where Gadelrab (2010) found that there was often an over-reliance on individuals rather than systems to provide food of consistent quality. On a theoretical level, Farrington et al. (2018) emphasized discomfort with the uncritical application of manufacturing techniques to the services industries in the earliest articles of their review. For example, Wyckoff (1984, p. 78) argued that "where manufacturing techniques have been applied to the service industries for improved consistency and productivity, services have too often become standardized, and personal interaction lost."

Some large multinational hotel chains, such as Ritz-Carlton have adapted TQM (Partlow, 1993), but the majority of restaurants within the hospitality industry are independent Small Medium Enterprises (SME's) without the resources or inclination to do so. Very few articles within the hospitality and tourism TQM literature focused on restaurants (Farrington et al., 2018; Wyckoff, 1984), nevertheless, Salameh and Barrows (2001) in their Canadian study of two chain restaurants concluded that a manager's ability to interview, hire, and train their employees effectively was the primary means that a restaurant has of achieving TQM. Meyer (2008) reinforces the importance of human capital, noting that his philosophy of hiring candidates with both emotional hospitality and technical ability underpinned the success of his businesses.

Gadelrab (2010) developed a bespoke quality management system based on ISO standards and appropriate for the production of food of consistent quality in hotels for his doctoral study of hotel restaurants in the Cardiff area of Wales, but noted the limitations of his research and the lack of generalizability of his findings. Another international system for food safety management, originating from food manufacturing, is Hazard Analysis Critical Control Point (HACCP), but Taylor (2008) identified twenty-one barriers to implementing HACCP and food safety management in hospitality, grouped into four separate units (External Behavior Barriers; Internal Behavior Barriers; Attitude/ Psychological Barriers; Knowledge/Expertise Barriers), some of which are pertinent to the phenomenon of FPF. These include the psychological concepts developed by Bandura (1977) of "outcome expectancy" and "selfefficacy," and also Pavlov's (1927) concept of "positive and negative reinforcement." Bandura (1977) argued that self-belief does not necessarily ensure success, but self-disbelief assuredly spawns failure. Taylor \& Taylor (2008) suggest that their Menu-Safe, and its shortened version, Safer Food Better Business (SFBB) food safety management systems for food businesses within the hospitality industry were the first in the world to be empirically developed and proven to work. Walsh and Leva $(2019$, p. 399) found in their own Irish 
study on food safety and in the literature from around the globe that food business owners need to commit "time and resources to identifying, risk assessing, and addressing the potential role of 'human error' in their facility whether intentional, unintentional, direct, or indirect." The influence of technological innovations on food preparation philosophies are presented by Rodgers (2008) in the light of impacts on food sensory and microbiological quality, nutritional value, and operational efficiencies.

\section{Leadership and management}

As the role of head chefs in setting the tune and orchestrating the performance in kitchens is important, they need to be transformative leaders rather than transactional leaders. Transformational leadership is a process of influencing 'in which leaders change their associates' awareness of what is important and move them to see themselves and the opportunities and challenges of their environment in a new way" (Kara et al., 2013, p. 10). Lee et al. (2013) found that transformational leadership impacted organizational climate which in turn significantly impacted employees' attitudes to follow safe food handling practices. Both Guchait et al. (2016) and Walsh and Leva (2019) found that high leader behavioral integrity for food safety could improve error reporting and error management leading to a reduction in the risk of foodborne illness, which was the ultimate goal of food safety training. The opposite of the transformational leader would be the "tyrannical chef," which a number of studies have identified as a barrier to implementing quality systems such as TQM, with many highlighting the lack of management control over kitchens, with chefs left to run their own domains (Gadelrab, 2010; Taylor, 2008; Zetie et al., 1994).

Chefs have been likened to "creative artists" (Middleton, 2000). "Imagination, inspiration, creativity" came as the first repository of inspiration for chefs in creating menus (Middleton, 2000). Wellton et al. (2019, p. 403), however, claim that "a dilemma for head chefs is that they often need to compromise between their professionality as cooking experts and their role as managers/leaders, the latter for which they are seldom trained." Furthermore, some chefs may not enjoy playing the leader (Wellton et al., 2019). Horng and $\mathrm{Hu}(2008)$ suggest a possible conflict between practical demands and creative interests of chefs. Balazs (2002) distinguishes between two roles of the chef, charismatic, and architectural. Charismatic can be regarded as a soft attribute, is about dealing with personnel while the architectural is more about the operational, managerial running of the kitchen.

Wellton et al. (2019, p. 416) argue that "... the practice of showing and guiding is a part of daily leadership, which is especially executed during preparation time in the kitchens." Executive chefs require specific competencies according to Wan et al. (2017) whose Taiwanese study developed a four- 
quadrant model divided into both hard (managerial and operational) and soft (behaviors and skills) competencies which illustrates the complex nature of managing a professional kitchen.

\section{Deskilling and turnover}

Cameron (2001, p. 104) charted the deskilling of Forte Hotel PLC restaurants from "à la carte" to "carvery" service and how this "radically altered the existing organisational climate, setting the stage for conflict between the 'organisation' and the cultural imperatives of chefs in respect of occupational identity." Robinson and Barron (2007) argue that labor mobility and attrition rates partly result from deskilling and standardization. They further divide labor mobility into the constructs of turnover (intra-occupational turnover), and attrition (inter-occupational turnover), pointing out that in Australia by the 10-year mark from initial occupational entry, up to $65 \%$ of chefs have left the industry. Birdir and Canakci (2014, p. 207) suggest that their Turkish study was the first to solely explore the managerial problems experienced at a kitchen context, pointing out that the most important problem confronting executive chefs was "finding educated/trained kitchen personnel." Turnover and shortages of chefs is a global issue which affects Ireland equally to Australia, the UK or indeed Turkey (Allen \& Mac Con Iomaire, 2016, 2017).

\section{Food production failure}

There is agreement that failures and errors are unavoidable in the hospitality and restaurant business (Guchait et al., 2016; Loo et al., 2013; Ozdemir et al., 2015; Yao et al., 2019). This is true in the more general service sector due to the multi-dimensional nature of the service encounter and "uncontrolled variability" according to Silber et al. (2009, p. 739). Unfortunately, failures can affect customers, employees, and establishments (Yao et al., 2019). For instance, errors can distress staff (Wang et al., 2020), and dissatisfy guests (Yilmaz, 2018). However, the focus should be on how to manage and handle errors (Wang et al., 2020), whereas it seems useless to try to prevent all errors from taking place (Frese \& Keith, 2015).

However, recovery mechanisms help to mitigate failures (Ozdemir et al., 2015; Yao et al., 2019). Chan et al. (2014, p. 224) observed that earlier studies on service failure concentered on staff-related and servicescape failure, however, they highlighted that "no studies have looked into the core element, product failures." Restaurant customers become organoleptically involved with their food. They are influenced by the texture, temperature, shape, feel, flavor, smell, and sound. If any one of these factors be inappropriate, the whole dining experience could be perceived as less than adequate (Brodsky-Porges, 1978; Kivela et al., 1999; Spence, 2018). Taste is considered the key attribute in 
food in the meal experience (Kivela et al., 1999; Namkung \& Jang, 2007), but taste is highly subjective and culturally constructed (Bourdieu, 1984). Consumers also expect safe food. Any physical, chemical, or biological contamination of food could lead to customer illness or worse, reputational damage, and even forced business closure (Chan et al., 2014; Chung \& Hoffman, 1998; Guchait et al., 2016; Loo et al., 2013).

Reasons for restaurant failure can be classified into internal, e.g.,, organizational culture, and external, for instance, taxation (Healy \& Mac Con Iomaire, 2019; Parsa et al., 2005). Restaurant continuation is more influenced by the internal elements than the external ones (Self et al., 2015). Among the internal elements, Parsa et al. (2005) delineated "poor product." Silber et al. (2009) identified some common service failures including defective dishes, out of stock, incorrect temperatures, wrong cooking temperatures, and incorrect orders. It is noted here that several of these are the sole responsibility of the kitchen staff; others are, arguably, shared between the server and the chef, while some are of a managerial nature. For example, "out of stock" items might be due to incorrect forecasting, supplier errors, or miscalculations by a chef. Incorrect temperatures could be ascribed to slow pickup by a server or the negligence of a chef. Food and drink or "product" is only one of the five aspects which make up a complete meal experience according to Gustafsson et al.'s (2006) Five Aspect Meal Model (FAMM); the others being "room," "meeting," "management control system," and "atmosphere."

Qualitative research by Ozdemir et al. (2015) discerned restaurant customers' complaints in Turkey relating to failures with regard to food, service, and atmosphere. In terms of food failures, their findings covered a myriad of issues, e.g., food safety, inadequate cooking, portion size, unavailable items, and improper temperatures. Similarly, Loo et al. (2013) studied service failure and online customer complaints in a cafe chain and full-service restaurant chain, and discovered that food-related complaints came in third place $(\mathrm{N}=1032,37 \%)$. Within this study, sensory quality (taste, texture, presentation, freshness, food condition) was the major source of discontent, followed by safety quality and finally other quality. Loo et al. (2013) believe that these failures could be easily eliminated. They advised management to scrutinize the origin of these sensory flaws and recommended implementing strict quality control checks on all processes involving food production up to the point of service. Chan et al. (2014) analyzed 450 online complaints from local-chained restaurants in Malaysia and identified three broad categories of productrelated failure (sensory quality, safety quality, and other) and 15 subcategories. Following HACCP guidelines, they divide the safety quality into physical, biological, and chemical contamination. The 'other' category included limited variety, small portions, missing ingredients, and no standardization. Notwithstanding this categorization, we do not know why such food failures happen in the first place. 
Using critical incident technique, Chung and Hoffman (1998, p. 68) delineated three principal categories of service failure, "service-system failures, failures in implicit or explicit customer requests, and unprompted and unsolicited employee actions." Under "service-system failures," a subset called "product defects" exists which included, for example, sodden food, foreign objects in food, and food which had not been thoroughly cooked. These food-related problems were the most cited in the participants' accounts, accounting for $20.9 \%$ of the incidents $(\mathrm{N}=373)$ (Chung \& Hoffman, 1998). Furthermore, as food was also the most recalled issue by their study participants, Ozdemir et al. (2015) advised restaurant operators to heed the quality of food. It is thought that identifying the shortcomings in the production of quality food items would alert management as well as educate chefs. Many of these flaws would be within management's control and remedies could be activated or sought. It is relatively easy to manage the tangible aspects of service. As a result, food lends itself to management's control (Gustafsson et al., 2006; Raajpoot, 2002).

\section{Listening to the staff}

Bitner et al.'s (1994) study discerned the employees' views on critical service encounters, which yielded significant insights. It should be noted here that, while there has been interest in listening to customers' complaints, complaints, and concerns raised by kitchen staff have rarely been given the same attention. Kitchen staff may be faced with obstacles that prevent producing quality food. Professional kitchens are hierarchical organizations and the culture, both good and bad, comes from the top, and is rarely questioned. Chefs' perceptions, intentions, and behaviors, which is influenced by their occupational identity or Bourdieu's term 'habitus' may directly affect FPF. The current research aims to give staff such a voice, whilst simultaneously addressing the gap in the literature. The practice of professional chefs in professional kitchens cannot be explained efficiently without analyzing it holistically, and from the perspective of the individual, the practitioners who create it. A practice framework will assist scholars in the field to see the larger picture behind the performance of successful practitioners (Kalogeropoulos et al., 2020).

Allen and Mac Con Iomaire (2016) building on the previous study in Cyprus by Zopiatis (2010), profiled head chefs in Ireland and identified competencies required for success in professional kitchens. The top three competencies identified were an ability to work hard, commitment to quality, and knowledge of HACCP which appear to cover the food safety and quality aspects of customer complaints mentioned in the literature (Chan et al., 2014; Chung \& Hoffman, 1998; Loo et al., 2013; Ozdemir et al., 2015). Kitchens are complex work environments which involve countless hours of work and demand sacrifices from their employees which can affect personal and family life (Borchgrevink et al., 1998; Pratten, 2003). Food production in professional kitchens is a multi- 
dimensional and complex occupation where FPF can occur for a variety of reasons. This is the first time this phenomenon has been qualitatively explored from the perspective of practitioners.

\section{Theoretical framework}

Aristotelian philosophy (both practical and ethical) can contribute in filling the theory-practice gap debated in organization studies (Kalogeropoulos et al., 2020). In Nicomachean Ethics, Aristotle presented the concept of phrónêsis, meaning the practical wisdom of an actor, possessing both the ethical and intellectual virtues. Aristotle also mentioned the term praxis, which is "the way from novice to expert and from tacit to articulate and it is also practice, training for competence development and insight" (Eikeland, 2012, p. 20).

There is a broader practice turn observed in the field of sociology, set by famous authors like Bourdieu (1984), Foucault (1977), and Giddens (1984). Moreover, De Certeau (1984) claims in terms of practice that it is of high value to identify how things are done and not just what is done. Schatzki (2018) provides a thorough overview of practice theory, identifying its first labeling as such by Ortner (1984) to name the ideas of Pierre Bourdieu and how the term has come to denote a stream of thought boasting varied theorists, both first generation (Pierre Bourdieu, Anthony Giddens, Jean Lave) and second generation (Stephen Kemmis, Elizabeth Shove, and Silvia Gherardi), whose ideas have been appropriated in numerous disciplines for the investigation of diverse social phenomena. Schatzki (2018, p. 153) identifies four features or "theories of practice": (1) they treat social life as composed, at least principally, of practice, which is not something one person alone can enact; (2) the world does not contain one practice but many; (3) social phenomenon are either aspects of, constellations of, or rooted in nexuses of practice; (4) the philosophical ideas of Wittgenstein (1957) and Heidegger (1962) form the background for practice theories, particularly the idea that human activity rests on something that cannot be formulated. This something has been variously conceived and labeled as habitus, practical consciousness, skills, and knowing how to go on.

Ferguson (1998, p. 628), using Bourdieu's field theory, defined the gastronomic field as a cultural field, "structured by the distinction between the material product - the food stuffs, the dish or the meal - and the critical, intellectual, or aesthetic by-products that discuss, review and debate the original product." Whereas Ferguson used texts by Carême, Dubois, Fourier, or Balzac to make her case, Fantasia (2018) brings the argument firmly into the twentieth century and beyond using the Michelin and Gault \& Millau travel guides and trade journals such as Néorestauration as well as culinary competitions such as the Meilleur Ouvrier de France (MOF) as newer forms of consecration. Two opposing logics, artisan high French gastronomy in the 
form of three-star fine dining, and industrial fast food, epitomized by the American McDonalds model, are juxtaposed. Fantasia explores how the two conflicting forms began to coalesce in the 1970s and 1980s, beginning with three-starred-chef Michel Guérard transferring his symbolic capital as a celebrity chef to economic capital by consulting with the frozen food industry and allowing them to add his name to frozen ready meals.

The gastronomic field is multi-layered and inter-related. Robinson and Barron (2007) identified that the social standing of chefs began to rise in the 1970s and continued to soar with the rise of food programming on television. Culinary practitioners (chefs) have a strong occupational identity and 'habitus.' The phenomenon of the celebrity chef based on consecration from the field can see chefs such as Guérard in France, Bayliss in the US, or Ramsay in the UK exchange symbolic capital for economic capital and build small empires.

This paper explores the phenomenon of FPF from the practitioner's perspective to find out not just what is done but how it is done (De Certeau, 1984).

\section{Research objectives and questions}

The objectives of this paper are to discover the chefs' concept of FPF, and to identify the different types of FPF and its causes. This research attempts to answer the following research questions:

RQ1.How do chefs conceive FPF?

RQ2.What are the types of FPF?

RQ3.What are the causes of FPF?

\section{Methodology and sample}

Phenomenology as an established philosophical movement gained credence with the writings of Edmond Husserl, Martin Heidegger, and later Maurice Merleau-Ponty among others (Gill, 2014). Ontological and epistemological views of leading phenomenologists differ from its two orientations (descriptive or hermeneutic) or its three associated methods (descriptive phenomenology, hermeneutic phenomenology, and interpretative phenomenological analysis) (Jackson et al., 2018; Kirillova, 2018; Pernecky \& Jamal, 2010). Pernecky and Jamal note "... significant variations within the phenomenological tradition .. .," pointing out that Heidegger's "hermeneutic phenomenology," which is the approach adopted in this article, " ... addresses experience from the perspective of meanings, understandings and interpretations" (Pernecky \& Jamal, 2010, p. 1056). Jonathan Smith's interpretative phenomenological analysis (IPA) is within the Heideggerian orientation and since its emergence (Smith, 1996), has become increasingly popular in psychology. IPA employs flexible 
guidelines and its idiographic nature distinguishes it from other phenomenological methodologies (Gill, 2014), making it apposite for this research.

Interest in the use of phenomenology in hospitality management methodological literature is growing (Jackson et al., 2018; Kirillova, 2018). Phenomenological research on chefs has also increased (Cousins et al., 2010; Gill \& Burrow, 2018; Robinson et al., 2014; Stierand et al., 2012), although Kirillova (2018, p. 3334) has been critical of inconsistencies and failure to acknowledge methodological stances in certain articles. To achieve the objectives of this exploratory study, constructivist ontology, an interpretive phenomenological epistemology, and a qualitative methodology was adopted. This can help to get close to the professional life and "lived experience" of the participating chefs to explore how they conceive and experience the phenomenon of FPF. A distinct advantage of qualitative research is that it permits unforeseen issues to come into sight, as it is "uniquely suited to 'opening the black box' of organizational processes, the 'how,' 'who' and 'why' of individual and collective organized action as it unfolds over time in context" (Doz, 2011, p. 583).

\section{Data collection}

Data was collected by the use of face-to-face semi-structured interviews with 15 chefs in different locations in the Republic of Ireland between February and May 2018 until data saturation was achieved (Gill, 2014). While 15 would be a relatively small sample in quantitative studies, it would be considered rather large for a qualitative sample, with some studies having between one and four interviews (Lepkowska-White \& Parsons, 2019). Kirillova (2018, p. 3336) notes " ... because phenomenological research involves richness of information to provide nuanced multilayered data, as opposed to thickness or quantity of data, data saturation tends to occur at relatively small samples." Purposive sampling (Smith, 1996) was used and the majority of interviewees held senior chef positions with many years of experience in various sectors of the hospitality industry (see Table 1). The sample included operations of different types. Both independent restaurants and hotel restaurants were targeted. Restaurants in hotels may have different rules and hotel chefs need to liaise with other departments and units within their operations and abide by established standards, resulting in potentially different dimensions to their accounts. Certain foodservice operations segments were avoided, fast food in particular, the reasons being that mass production outlets are standardized to such a degree that virtually no discretion is left to production staff (Reiter, 1996; Rodgers, 2008). Systems are strong in chain restaurants or Multi National Company (MNC) hotels, neither of which are significant players in the Irish hospitality market, with smaller independent operators dominating. Only one MNC hotel chef was interviewed. 
Table 1. Outline of participants.

\begin{tabular}{|c|c|c|c|c|c|c|c|c|}
\hline $\begin{array}{l}\text { Code } \\
\text { Alias }\end{array}$ & Gender & Age & Position & $\begin{array}{l}\text { Years in } \\
\text { Foodservice }\end{array}$ & $\begin{array}{c}\text { Highest } \\
\text { Educational } \\
\text { Qualification }\end{array}$ & $\begin{array}{c}\text { Type of } \\
\text { Establishment }\end{array}$ & $\begin{array}{l}\text { Years in } \\
\text { Current } \\
\text { Position }\end{array}$ & Location \\
\hline Mary & Female & $31-40$ & Head Chef & 21 years & $\begin{array}{l}\text { Advanced } \\
\text { Certificate }\end{array}$ & Restaurant & 7 years & City \\
\hline David & Male & $41-50$ & Head Chef & 30 years & $\begin{array}{l}\text { Advanced } \\
\text { Certificate }\end{array}$ & Restaurant & $<1$ year & Rural \\
\hline James & Male & $41-50$ & Exec Chef & 26 years & $\begin{array}{l}\text { Bachelor's Degree } \\
\text { (Ord) }\end{array}$ & Hotel & $<1$ year & Rural \\
\hline Brian & Male & $31-40$ & Head Chef & 13 years & $\begin{array}{l}\text { Bachelor's Degree } \\
\text { (Hons) }\end{array}$ & Restaurant & 3 years & City \\
\hline Martin & Male & $31-40$ & Chef/Owner & 17 years & $\begin{array}{l}\text { Advanced } \\
\text { Certificate }\end{array}$ & Restaurant & 5 years & Rural \\
\hline Linda & Female & $31-40$ & Chef/Owner & 20 years & $\begin{array}{l}\text { Bachelor's } \\
\text { Degree (Ord) }\end{array}$ & Restaurant & 3 years & City \\
\hline Conor & Male & $41-50$ & Exec Chef & 25 years & $\begin{array}{l}\text { Advanced } \\
\text { Certificate }\end{array}$ & Restaurant & 1 year & Rural \\
\hline Cathal & Male & $50+$ & Exec Chef & 32 years & $\begin{array}{l}\text { Post-Graduate } \\
\text { Degree }\end{array}$ & Hotel & 17 years & Rural \\
\hline Thomas & Male & $31-40$ & Head Chef & 20 years & $\begin{array}{l}\text { Bachelor's } \\
\text { Degree (Ord) }\end{array}$ & Restaurant & 5 years & City \\
\hline Catherine & Female & $31-40$ & Head Chef & 20 years & $\begin{array}{l}\text { Bachelor's } \\
\text { Degree (Ord) }\end{array}$ & Restaurant & 5 years & City \\
\hline Colm & Male & $50+$ & Relief Chef & 55 years & $\begin{array}{l}\text { Advanced } \\
\text { Certificate }\end{array}$ & Hotel & 5 years & Rural \\
\hline George & Male & $41-50$ & Head Chef & 27 years & $\begin{array}{l}\text { Advanced } \\
\text { Certificate }\end{array}$ & Hotel & 1 year & City \\
\hline Sean & Male & $41-50$ & Chef/Owner & 22 years & $\begin{array}{l}\text { Bachelor's } \\
\text { Degree (Ord) }\end{array}$ & Restaurant & 3 years & Rural \\
\hline Seamus & Male & $31-40$ & Chef/Owner & 22 years & $\begin{array}{l}\text { Advanced } \\
\quad \text { Certificate }\end{array}$ & Restaurant & 10 years & City \\
\hline Diarmuid & Male & $31-40$ & Exec Chef & 17 years & $\begin{array}{l}\text { Bachelor's } \\
\text { Degree } \\
\text { (Hons) }\end{array}$ & Hotel & 2 years & City \\
\hline
\end{tabular}

A flexible interview guide (Giousmpasoglou et al., 2018) was created to reflect the main questions which the research attempts to explore. These focused on the concept, types, and causes of FPF. The guide was reviewed by the three researchers, and a pilot interview was carried out with a chef colleague of one researcher to identify any discrepancies. Following feedback from the pilot interview, to ensure a consistent understanding of the definition of FPF, participants were reminded at the outset of each interview that FPF occurs up until the food leaves the kitchen. Each interview commenced with general questions about work experience, demographics, and professional background, gradually elaborating with respondents on specific aspects of their lived experiences of food production failure. The flexible guide included sections on food quality definitions and attributes; staffing and business volume; food production failure; effects of failure and recovery on kitchen staff; relationships between the kitchen and front of house $(\mathrm{FOH})$ and restaurant owner/manager; and finally, production recovery. Some typical questions were: How do you define food quality? What controls are in place to ensure quality of standards are kept? What would you classify as FPF? Have you experienced FPF and can you give some examples? What methods do you 
employ to prevent FPFs recurring? What support do you receive from the restaurant management/owner(s) to resolve FPF? Where do you get your ideas to resolve problems? Although the guide was followed, a degree of flexibility was permitted which allowed discussions on related topics to develop and rich data to emerge (Gill, 2014; Smith, 1996). Notes and memos were taken during each interview; these were appended to the transcripts for use at the data analysis stage.

The longest interview took 56 minutes while the shortest interview lasted 32 minutes. Interviews were transcribed verbatim amounting to a total word count of 48,218 (136 pages). The transcripts were then checked against the recordings for accuracy. Participants were asked to sign a consent form. Each was assured of complete anonymity - of both identity and operation - and data confidentiality. Names used within this paper are pseudonyms (Table 1).

\section{Data analysis}

The data were subjected to qualitative inductive thematic analysis (Braun \& Clarke, 2006), which involved a process of data familiarization, coding, and gradual data reduction as coded comments were brought together under higher order themes. Codes were subjected to a process of continual comparison, and the data were refined through several stages using procedures outlined in the literature (cf. Braun \& Clarke, 2006; Gill, 2014; Lepkowska-White \& Parsons, 2019; Quigley et al., 2019; Smith, 1996). Analysis in qualitative research does not stop by summarizing data; it digs deeper to recognize patterns and themes envisaging the relationships among these reaching to an elucidation of the phenomenon. It should be noted, however, that this process was an iterative one (Gill, 2014). During and after the analysis, certain codes were canceled, others were created; some data segments were recoded, some were deemed a better fit for a different theme than the one to which they had initially been assigned. The final outcome of the analytical process is a narrative account where the researchers' analytic interpretation is presented with verbatim extracts from the interviewees (Gill, 2014). To assist with the analysis, QDA Miner Lite computer-assisted qualitative analysis software was used. Robinson et al. (2014) argue that using qualitative analysis software augments the integrity of data management.

\section{Credibility, dependability, and transparency}

To enhance the "credibility" and "dependability" of the process, a number of procedures were followed. Coding was carried out independently by two of the researchers working in parallel to provide "researcher triangulation" (Denzin \& Lincoln, 2000). The two codings were then brought together for comparison and discussion in order to identify differences and similarities in analysis. An 
inter-rater-reliability test was conducted using Cohen's (1960) coefficient formula (Appendix A). The codes employed by the two researchers in the first four questions on the interview guide of two of the participants were used to create the data required for insertion in the Kappa formula. The result gave an average kappa coefficient of .78. This figure according to Landis and Koch (1977) would have the coders at substantial agreement. The third researcher was charged with the role of "code-book editor" to manage the multiple codings, as recommended by Robinson et al. (2014). To add a further level of trustworthiness, reflexivity was adopted as a research tool throughout the entire research process. As two of the researchers held occupational experience as professional chefs, an emic rapport (Robinson et al., 2014) was developed with the interviewees. This facilitated a greater level of insights and a reflective hermeneutic cycle (Heidegger, 1962) which continued into the analysis and beyond, increasing the rigor of the project. Interviews are clearly reflexive, but reflexivity comes into its own in the interpretation and reinterpretation of data - Heidegger's (1962) “double hermeneutic" manifest. May (1999) describes knowledge derived from the shared understanding of a community (chefs) based on the emic posture of the researchers as "endogenous reflexivity." Robinson et al. (2014, p. 71) reinforce the strength of reflexivity, discussing Bourdieu's three-dimension model, and concluding that the process of writing itself is a "highly reflexive practice." After highlighting that reflexivity is not immune to criticisms from academics, Robinson et al., conclude that "... ultimately reflexivity facilitates the telling of a story, or describing a phenomena, from a particular perspective ..." which is consistent with a phenomenological epistemology (Robinson et al., 2014, p. 71).

This research paper fulfills the majority of the transparency criterion outlined by Aguinis and Solarino (2019). The phenomenological approach is overt, the emic nature of the researchers is highlighted, purposive sampling was used, research setting identified, saturation point discussed, data coding by multiple coders and inter-rater-reliability measured, and reflexivity adapted throughout the entire process. Future studies might benefit from applying additional criterion such as the relative importance of the participants/cases (Aguinis \& Solarino, 2019).

\section{Findings}

\section{Participants' profile}

The demographics of the interviewees are discussed here and an outline of participants is shown in Table 1 . Male chefs constituted $80 \%$ of the sample while female chefs accounted for $20 \%$. The majority of the participants were aged between 31 and 40 years, five participants were in the 41-50 age-group and two participants were over 50. Most of the participants had a long history 
of working in food service, 367 years in totals, the mean was 24.47 years. Chefs acquired their experience in various types of establishments, however, at the time of interview ten $(66.6 \%)$ chefs were employed by independent restaurants while five $(33.3 \%)$ worked for hotel restaurants. The majority held the title "head chef," "executive chef," or "chef/owner" while just one worked as a "relief chef," although previously employed as an "executive chef." The shortest period spent in a current position was less than 1 year; the longest serving individual had 17 years, while $40 \%$ of those interviewed had spent between 5 and 10 years in their current position.

\section{Findings and discussion}

\section{Concept}

All interviewees acknowledged experiencing FPF's at some time and were forthcoming with examples of their concept of FPF based on their lived experiences. These ranged from issues with suppliers concerning the quality of food supplies (bad procurement, bad quality food, not checking deliveries, poor storage etc.) to operating procedures preparing the food (not weighing ingredients, missing ingredients, incorrect proportions etc.) to production (over/under cooking, over/under seasoning, smell, presentation, temperature etc.). One issue which was unanimous was the effect FPF had on morale in the kitchen, notably, that it led to embarrassment, frustration, and bad feeling. Failure damaged the positive atmosphere of teamwork, family, and flow (Csikszentmihalyi, 2008) that were generally felt in kitchens when production and service were going smoothly, as earlier described by Daniel Boulud (cited from Eburne, 2010, p. 173). The consequences of FPF, however, are outside the scope of this paper, but warrants further study.

Mary's concept of FPF is “ ... any accident really; food getting dropped, broken or damaged, food getting burned or overcooked. Just anything going wrong, things getting made wrong or sauces splitting, that sort of thing." James conceives FPF as " ... something that is caused by the kitchen, something returned, something that is not right, you have to class it as a food production failure." David mentioned overcooked foods. However, failures mean both failed systems and failed overseers, according to Brian " ... because we have so many systems in place to catch these issues before it gets to the pass, that it would have to be myself or my sous chef to blame." There is a belief, however, that things have changed for the best as Colm observes " ... everything seems to have improved ... you also had changes in equipment for the better over the years, suppliers started delivering better quality produce, you did not have to be returning as much stuff as you did in the early days." This comment ties in with Rodgers (2008) findings that technological innovation is crucial to sustain competitiveness. 
One theme that was universal to how all participants conceived FPF was the inevitability of mistakes, mostly caused by human error. Another universal response was the importance of staying calm when FPF's occur. Cathal straightforwardly states that " ... we all have had loads of examples of this, if anyone says they do not have any [FPF's] they are fooling only themselves." Brian notes that "... this is a rollercoaster that never stops ...", hence, he believes they have to be quite vigilant. The problem is "the mistakes are greater with the more people; the more hands that touch the food, the more things that can go wrong." Notably, Brian concluded that "... we try and cover everything as much as we can. Everybody is a human being, everybody makes mistakes."

One of the interesting issues is how participants conceived the temporal conditions of kitchens affecting FPF. Seamus suggests that " ... when you are not busy that is when mistakes happen. It is easier when it is busy.” Discussing the relationship between front of the house and kitchen, Diarmuid notes “... during the busy services it tends to be better than the quiet services. When it is quieter, people tend to take their eye off the ball and be a bit more relaxed." Mary does not share this opinion, and justifies this, " ... mistakes tend to happen more in busy times, [as] people are more under pressure ..."

George conceives FPF incidents and staff responses to these as opportunities to learn; "We can make a mistake once, learn from it and move on." Some examples of learning from mistakes in the data include the use of timers to avoid overcooking of food, and the use of the software application "WhatsApp" to avoid communication-related failure. When failures occur, Cathal tries to " ... talk to them [staff], tell where they went wrong, tell how to fix it, if it is fixable ... They must learn from mistakes not keep repeating them." These comments fit in with EMT discussed in the literature (Yao et al., 2019). Seamus believes in honesty and trust, and has a special notebook where they log mistakes and try not to repeat them. However, Cathal noted that "... once is an accident, twice is carelessness, but three times is unacceptable." Although he had only sacked one employee in his 25 years in the foodservice industry, Conor sagely noted that "... being understaffed is never a reason not to sack someone." He concludes that bad employees are negative "... like a cancer, it can spread through the whole kitchen ..." , and it is better to be understaffed than have negative workers. These comments chime with the importance of good recruitment and staff selection (Meyer, 2008; Salameh \& Barrows, 2001).

\section{Types and causes of FPF}

Participants were asked to give examples of FPF from their current operations or from previous posts. Some FPF, according to Linda seem ridiculous “ ... instead of using wine, people use white wine vinegar, mixing up sugar and salt ..." These are "sensory/organoleptic" in nature as they would affect the 
taste of the final dish. All of the senses feature in FPF, tough meat can have the wrong texture, wrong temperature in a dish is also a sensory issue, not to mention that presentation and smell are among the first senses we use in selecting our food and deciding what we will ingest. However, some types of FPF are significant as they represent a health hazard as Linda states “... bugs in the salad as it has not been washed properly ..." Diarmuid recalls a potential physical health hazard caught by mere chance, as he discovered a piece of broken glass in food before service. These are "safety" in nature and following HACCP principles, they can be subdivided into biological, chemical, or physical. Notably, these health and safety/hygiene failures were the least noted among the interviewees, which may tie into knowledge of HACCP being among the top three competencies noted by Irish head chefs for success (Allen \& Mac Con Iomaire, 2017). Following the typology in the literature (Chan et al., 2014) the "other" type of FPF includes Mary's examples of "food getting dropped, broken or damaged, food getting burned or overcooked" as these damaged foods need to be discarded (food waste) and there is a cost associated with the replacement and re-work of the food, both of which were identified as factors in the literature (Okumus, 2020; Ramdeen et al., 2007). Among the "other" type of FPF in this study are communications related failure, systems related failure, lack of supervision, and standard operating procedures.

From initial analysis of the data, six main causes of failure (people, layout, menu, equipment, food supply/supplier, forecast) were shortlisted but on further analysis they were reduced down to four types of failure (people, supply, foodservice industry, operation) with 32 examples or sub-sets of causes, as seen in the fishbone diagram (Figure 1). People-related failure was the largest cause with 14 examples ranging from lack of communication, training, and tiredness, to lack of supervision, attitude, and wrong technique. Operation-related failure was next with eleven examples such as menu design, kitchen layout, and unskilled staff. The "supply" and "foodservice industry" sections are the least populated in Figure 1. Following reflection, the "foodservice industry" and "operations" sections were integrated for the final themes.

The Venn diagram in Figure 2 depicts the crossover between different causes where it comes to the individual issues of lack of supervision, fatigue, lack of training, consequences of kitchen staff turnover, wrong techniques, order-filling issues, commodities discrepancy, uncertainty, and work conditions (Heberle et al., 2015). For example, lack of supervision (LS) is shared between people and operation, as when senior employees fail to assume their supervision roles, junior or trainee staff may be more likely to err. As shown in the Venn diagram, the least overlap occurs with produce/supplier. On the other hand, operation and foodservice industry have the highest intersection. Industry could also be conceptualized as organizational climate and culture, as it concerns how certain practices are carried out in certain organizations or industries. 


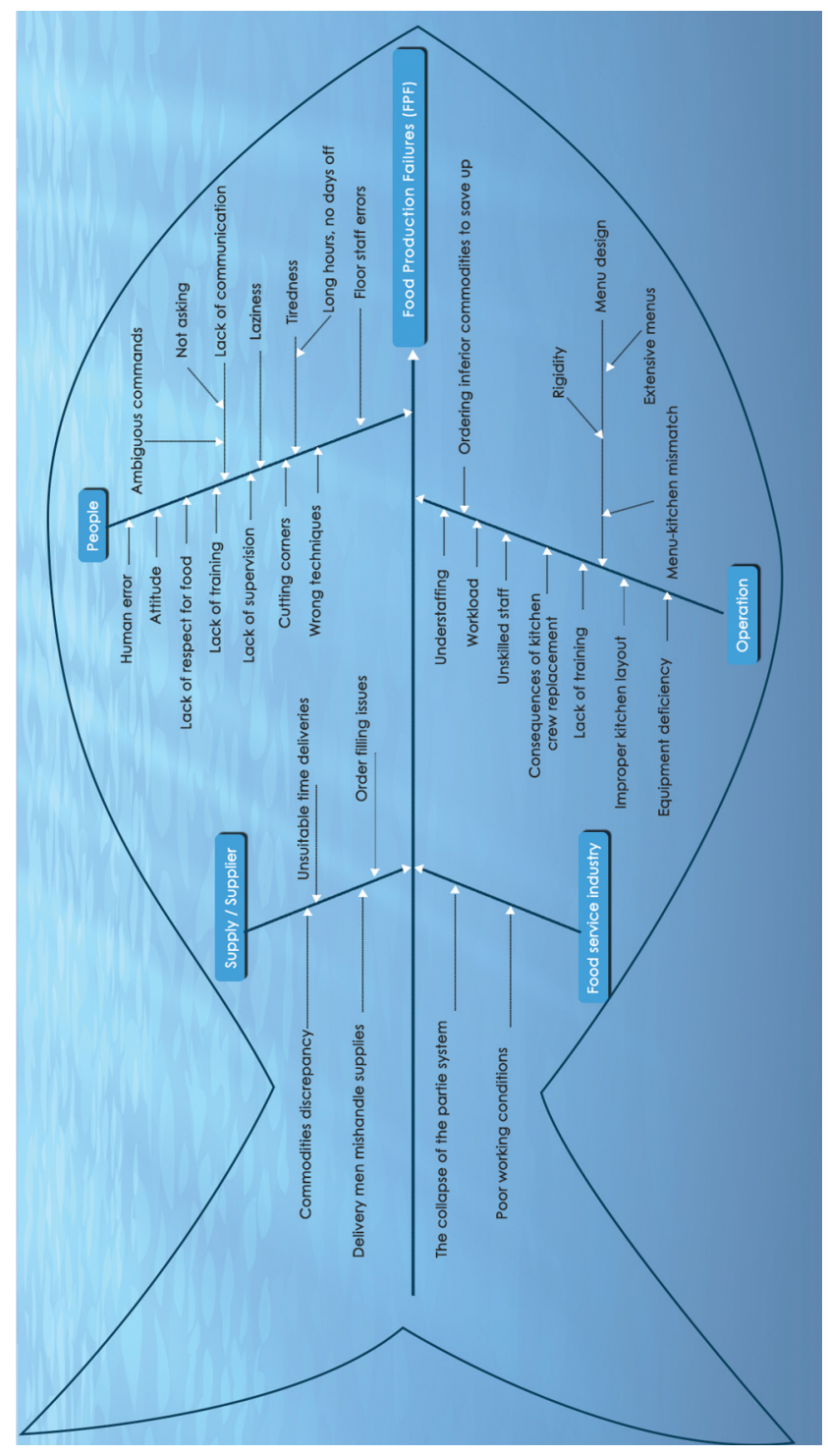

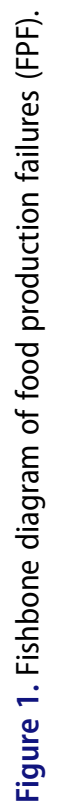




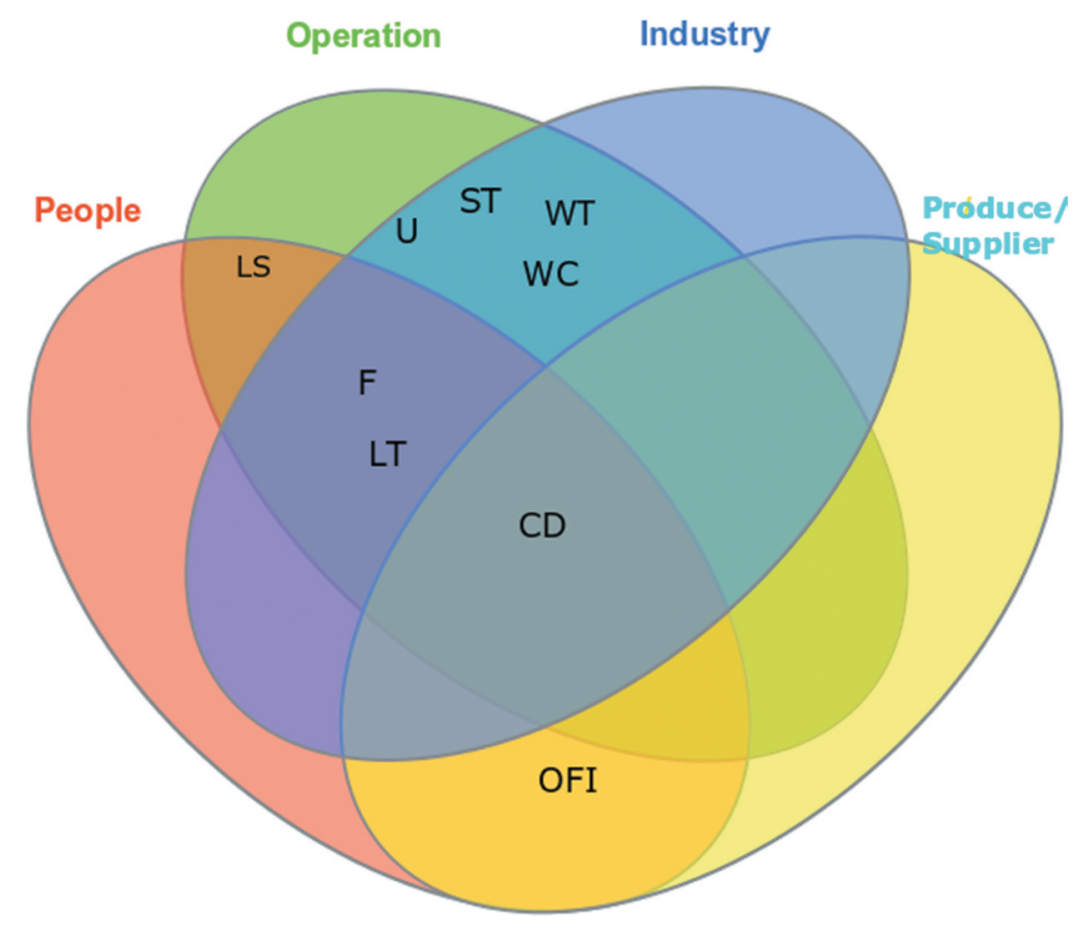

Figure 2. Overlapping causes of FPF. Key: Lack of supervision (LS), Fatigue (F), Lack of training (LT), Consequences of kitchen staff turnover (ST), Wrong techniques (WT), Order filling issues (OFI), Commodities discrepancy (CD), Uncertainty (U), Work conditions (WC).

\section{Three main causes of FPF's}

Following the final stages of thematic analysis, the study identified three main causes of FPFs. Human error is one of the biggest issues in FPF but Reason (2000) notes that two approaches to human fallibility exist: the person and the systems approaches. The person approach focuses on the errors of individuals, blaming them for forgetfulness, inattention, or moral weakness. The system approach concentrates on the conditions under which individuals work and tries to build defenses to avert errors or mitigate their effects.

People-related failures. Human error has been outlined above as a main cause of FPFs. This category can include internal actors such as chefs and kitchen porters, or external factors such as delivery personnel. For example, David dislikes people mishandling supplies upon receiving and storing. Cooking is full of chances for people to cause FPF, as Thomas cites "... someone walks out and leaves a pot on full blast, especially something like rice or even a polenta, it burns at the bottom and all of it is gone..." The causes of peoplerelated failure are diverse. Seamus stresses the importance of humans as “... this industry is solely reliant on people. There is always talk about robots eventually doing all our jobs for us. I don't think that will happen. Maybe in 
a larger corporation but in the restaurant industry, we are so dependent on good people, with good training." Rodgers (2008) noted that future innovation may originate in the field of robotics but that they were more likely in industrial cuisine than in fresh food restaurants. Unfortunately, people are a major cause of FPF. There are two main subclasses identified here: inadvertence and poor attitude.

Some mistakes are unintentional, as Thomas describes “... people forget stuff, bread soda in bread mix, seasoning in dishes, mixing salt for sugar and vice versa." Not paying attention is a reason, as Sean mentions, "... I have even seen a chef forget to put flour in a sponge and then wonder why it wasn't cooking." Mary believes that " ... the main cause is carelessness before human error. Everyone makes mistakes but if you're just being lazy about it, it's not really a mistake." This is very much Reason's (2000) person approach. Similarly, George and Thomas cited carelessness. Thomas argues that "the biggest problem is other people. This is followed by their attitude towardswork ..." Sean notes that negligence comes down to whether the person cares about food or not and this relates to their attitude toward the work "... to some it's just a job but to others it is a career. It makes a big difference ..."

Other people-related causes of FPF include tiredness due to overwork, understaffing, long hours and a lack of time off. Lack of communication is an additional cause of people-related FPFs and ranges from staff not asking questions to ambiguous commands (Figure 1). A classic example of this is the tale of "... the chef who asked a new kitchen porter to drain a pot of beef stock. When he returns to see a pot of bones waiting for him he explodes with anger on finding that the porter had poured the liquid (8 hours of gentle alchemy) down the drain" (Mac Con Iomaire, 2008, p. 50). Among the final peoplerelated causes of FPF are incorrect techniques, lack of training, and lack of supervision, although there is some crossover with operations related failure. Walsh and Leva (2019) highlighted the "human factor" in food safety and noted that a high standard of training and appropriate implementation of food safety principles is necessary to safeguard modern food businesses.

Operations related failures. Operations related failures cover a number of factors including layout, design, work process, workload, menu design, and equipment deficiency. Reason's (2000) systems approach to human fallibility fits here. The ensuing causes lie within an operation's discretion; hence, they can be largely controlled. Mary complained about her kitchen layout. Extensive menus can result in customers requesting different items at once; this puts pressure on the kitchen, which leads to FPF. Mary was concerned about the food temperature, " ... the food is sitting on the pass with no heat lamps obviously it is going to go cold." This is exacerbated in high demand times.

Catherine observed that her food production was stifled by "... the menu not matching the kitchen." They had fish and chips, and burger and chips on 
the menu but only two fryers in the whole kitchen. "The fish then takes over a whole fryer ... So, we changed the menu." Brian designed his menu to have both hot and cold starters and to have the pastry section do a small appetizer to take pressure off the other sections. This is down to good menu planning (Kivela, 1994). James views an extensive menu as a cause of failure: "If you have a menu as big as we have, which is like 70 odd main courses, and a 200seater restaurant and a party of 40 , you cannot keep doing it."

A major cause of FPF was lack of supervision. David feels that his presence makes a difference, " ... when I am on, it will be to how I want it and how it should be, when I am off, hard to say, they might cut a few corners." There was widespread agreement from all interviewees of the need for good relationships with $\mathrm{FOH}$ to ensure all orders do not arrive at once - to stagger the rush. The concept of "them and us" was frequently mentioned but mostly in a historic sense which suggests relationships and communication between kitchen and FOH staffs were improving. The need for an experienced supervisor or manager on the pass, dispatching the food at busy periods was also widely noted. Other operational causes of FPF include poor kitchen layout/ergonomics, lack of training, understaffing, and equipment deficiency such as Mary's lack of heat lamps and microwaves. Many of the risk factors associated with foodborne illness including cross-contamination, and inadequate cleaning and sanitation of equipment and work surfaces (Walsh \& Leva, 2019) could be grouped as operational, in that proper work processes were not being followed.

Food supply/supplier-related failures. The need to have consistency and trust with your supplier was noted by all interviewees. Communication is paramount as to precisely what is required, when it needs to be delivered, how it should be handled by the delivery person and what alternatives are available. Brian labels this "flexibility" for example, if turbot is not available, he will happily use brill or halibut, and communicates the new alternative to the customer in a clear manner. Food supply is a prime concern for chefs as suppliers may provide substandard commodities. However, once these are received by the kitchen staff it becomes their responsibility. Nevertheless, in some cases checks may need to include the "kill date," as James noted about cooking a T-bone steak that was tough. This highlights that some aspects of quality depend on experience and may not be picked up by younger trainees. Rodgers (2008) posits that restaurants would benefit from analytical instrumentation for testing raw produce. Failure can be exasperated if the chefs know but cannot control the quality of their supply. Martin vents his frustration, “... when I was in [restaurant name] we were buying lovely beef but suddenly [the manager] did not want to pay the prices anymore, so he bought it from someplace 
else and the beef was tough, and I kept telling him and he kept saying it was fine. I did not want to serve it, but I had to." The procurement of substandard cheap produce can lead to tension with the chef and kitchen brigade who feel demoralized serving what they know to be inferior food.

\section{Conceptual model of FPF}

In coding the data and its thematic analysis, it became apparent that certain key themes (communication, supplier confidence, staff attitude, characteristics, and training etc.) were more dominant than others (hygiene, equipment, and storage etc.). Reflexivity and continuous iterative thematic analysis led to the development of a conceptual model of FPF (Figure 3) which could help turn FPF into food production success (FPS). The three key types were "sensory/organoleptic," "safety", and "other." The three key causes were

\section{Management Control System}

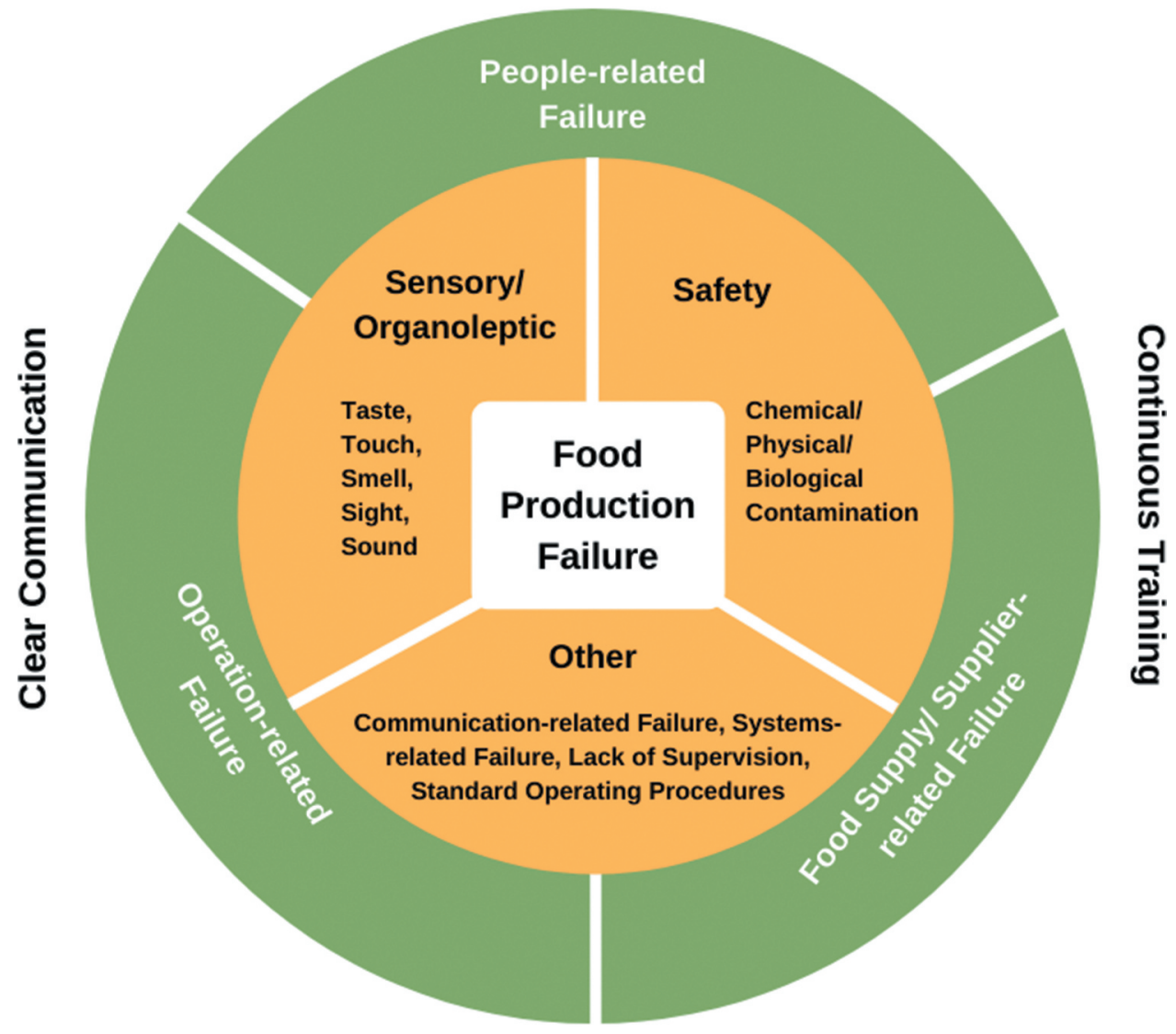

\section{Organizational Culture/ Climate}

Figure 3. Conceptual model for food production failure (FPF's). 
people-related failure; operation-related failure; and food supply/supplierrelated failures. These were however underpinned by a lack of management control systems, lack of continuous training, lack of clear communication (verbal, written, and visual), and were strongly influenced by the organizational culture and climate of the kitchen. Gustafsson et al. (2006) defined the management control system as the rules, laws, and economic and management resources backstage that are needed to make the meal possible. One of the significant themes emerging from the data was both the organizational culture and the climate of kitchens. Each interviewee was adamant that whatever FPF occurred in their kitchen, it was up to them and them alone to fix it. Professional kitchens and their culture formed a habitus, to use Bourdieu's (1990) term, a practice which was deeply integrated and, most likely, rarely questioned. The habitus of the kitchen brigade trying to work at peak performance while understaffed and using broken equipment was previously highlighted by Mac Con Iomaire (2008). Kitchens are part of the larger hospitality organization and "error management" needs to apply across the whole industry. Error management is a strategy that focuses on minimizing the negative consequences of errors by early detection and quick error correction, and on preventing similar errors in the future by analyzing what caused the errors and learning from errors (Hofmann \& Frese, 2011).

Guchait et al. (2018) posit that organizational error management culture within the hospitality industry impacts organizational performance, management-team performance, and creativity. The unique organizational culture of kitchens has been previously studied (cf. Fine, 1996; Gill \& Burrow, 2018; Giousmpasoglou et al., 2018), often focusing on the negative aspects of bullying, stress, or fear. One interviewee, Seamus, highlighted that in some restaurants "... you can almost taste the fear in the food ...", whereas in his restaurant " ... [h] opefully here you can taste the love in the food and that's what we strive for." Leadership, therefore, is extremely important in kitchens. Lee et al. (2013) found that transformational leadership style influenced organizational climate which, in turn, impacted employees' attitude.

Organizational climate (OC) is defined as employees' shared perceptions of organizational policies, practices, and procedures, as well as the types of behavior that are rewarded and supported in the workplace (Lee et al., 2013). A dominant theme emerging from the data was "attitude" with some interviewees preferring to remain understaffed than having staff with the wrong attitude. This fits in with Meyer's (2008) theory of emotional hospitality where he asserts the importance of hiring employees with the correct attitude. This, in turn, leads to the pillar of continuous training, which is a major issue particularly in an industry with staff shortages, high turnover, and also a high proportion of "college staff" who are not pursuing a career in hospitality but merely earning a wage while in further education. Mac Con Iomaire (2008) highlighted the importance of training and proposed "mentoring" as a model 
to nurture culinary talent, which has been championed by Giousmpasoglou et al. (2018). Kalogeropoulos et al. (2020) noted that $82.3 \%$ of the cohort in their study had at least one mentor at some time in their career. Forthcoming research by one of the authors has asked chefs if they would prefer to be better at recruiting or at training, the results of which highlight Meyer's (2008) philosophy that careful recruitment ensures training will be much more productive. EMT sees that errors can be an integral part of training (Yao et al., 2019). People are paramount to success. Managing "human error" is central to reducing FPF (Guchait et al., 2018; Reason, 2000).

\section{Conclusions}

The chefs' concept of FPF was that it was inevitable, based on human error, which ranged from procurement and supplies, operational procedures preparing food, to poor production and execution of dishes. This included failed systems and failure of oversight or supervision. There was broad agreement that both equipment and supplier quality had improved over time, but opinions varied as to the temporal nature of when FPF was most likely to occur. FPFs, however, were conceived as learning opportunities, which ties in with Yao et al.'s (2019) paper on EMT. Nevertheless, continuing to employ negative staff who repeatedly made errors was considered unacceptable. The importance of human capital and good recruitment and training policies was highlighted in the literature (Meyer, 2008; Salameh \& Barrows, 2001). The types of FPF could be categorized as "sensory/organoleptic," "safety," and "other" similar to the literature (Chan et al., 2014), however using thematic analysis, this study identified three main causes of FPF (People, Operations, and Food Supply/Supplier) and proposed a conceptual model (Figure 3) to help transform FPF into food production success (FPS).

While the exploratory qualitative methodology precludes making generalizations that apply to the industry as a whole, the findings of this research enhance the literature on professional chefs and kitchens and particularly address the significant gap in literature in relation to FPF. This exploratory paper provides the first tesserae of what may become a mosaic. Further publications from this project should provide a clearer picture of the phenomenon of FPF, and further research into the phenomenon of FPF will bring the overall picture into sharper focus. This research is significant for a number of reasons. The implications of this research are threefold: (Theoretical, Practical, and Managerial). It highlights, for the first time, why kitchens fail and it explores the concepts, types and causes of FPF, from the "lived experience" of professional practitioners, which should lead to reduced frequency of FPF. From a practical perspective, reduced incidence of FPF will increase job satisfaction and thus may reduce staff turnover, lead to improved customer satisfaction, repeat business, and increased revenue (Gupta et al., 2007; 
Susskind, 2002), reducing the cost of quality (Ramdeen et al., 2007), and also reduce food waste in restaurants, a particularly topical issue (DiPietro et al., 2013; Okumus, 2020). In addition, this research contributes to the increasing phenomenological studies within hospitality management (Kirillova, 2018), in particular, the historically underrepresented research on chefs and kitchens (Allen \& Mac Con Iomaire, 2016: Cooper et al., 2017; Zopiatis, 2010). The researchers' emic approach, tempered by reflexivity provides rich thick data on the phenomenon of FPF and the paper fulfills the majority of the transparency criterion outlined by Aguinis and Solarino (2019).

Theoretically, the conceptual model (Figure 3) acts as a starting point toward building a theoretic framework for food production failure (FPF). As Reason (2000, p. 769) noted that “... medicine knows more about disease than health ...," current hospitality literature may know more about the cause of restaurants failure than how failure can be avoided. Theoretically, the use of practice theory and particularly Bourdieu's theoretical toolbox adds to the understanding of the occupational identity and 'habitus' of professional chefs, and also their 'praxis.' Furthermore, the concept of error management and EMT will be useful in further developing the research on FPF in restaurants (Frese \& Keith, 2015; Guchait et al., 2018; Hofmann \& Frese, 2011; Yao et al., 2019).

The managerial implications for this research are to inform management (Kitchen managers - executive, head, and sous chefs - and General managers hotel, restaurant, purchasing, and operations managers) of the types and causes of FPF, particularly those tangible elements which are within management control (Gustafsson et al., 2006; Raajpoot, 2002). This study may help them reflect on the way they plan, design operations, recruit, supervise, train, people they allocate and how they spend budget, time, and effort. It also alerts senior management of the need to have the kitchen management (head chef or executive chef) included in organizational planning and to consult with them and value their practical knowledge (praxis) as opposed to enforcing ideas from above with no understanding of how they may practically affect operations in the kitchen. Equally, the days of the "Tyranical chef" must be over (Zetie et al., 1994). Chefs need to become more transformational leaders (Kara et al., 2013; Lee et al., 2013), challenging negative 'habitus' within kitchens, changing organizational culture, and in turn significantly impacting employees' attitudes to follow safe food handling practices, quality food purchasing, handling, and storage, consistent quality in food preparation, production, and presentation, and thereby significantly reducing the phenomenon of FPF.

\section{Limitations and proposed further study}

Several limitations arose during the course of the research. Space was one limitation, as only a fraction of the research findings could be presented in 
a single paper. Areas for proposed further study are identified below. A further potential limitation of this article is the methodology applied. Many researchers criticize the perceived lack of rigor and application of phenomenology and qualitative research. Phenomenological theorists lack agreement around issues of best practice such as epoché or bracketing in Husserl's descriptive phenomenology which is disputed in Heidegger's interpretative approach (Gill, 2014) adopted in this research. Issues of bias, preconceptions, and the subjective researcher's influence on the analysis of the data have also been questioned; although Robinson et al. (2014, p. 69) argue that this can be counteracted by Denzin and Lincoln (2000, p. 19) quote that "... [t] he age of value-free inquiry for the human disciplines is over."

Another limitation of this research is that although it incorporates voices from urban and rural areas, and from independent restaurant and hotel kitchens of various sizes and grades, the research was carried out solely in the Republic of Ireland. Chain and MNC hotels that have strong systems and (SOP's) are not significant players in the Irish hospitality market. The lived experiences of chefs working in these types of establishments, and in other countries or regions of the world may differ. Gender is also an issue, as over $30 \%$ of chefs in Ireland are female while only $20 \%$ of the interviewees were female.

Many of the factors which influence FPF overlap and further details from the study, such as the overlap of communication and technology (i.e. WhatsApp), error management in kitchens, consequences of FPF, or strategies for FPF recovery, drawing on the service recovery literature are all areas ripe for further study. Following more exploratory studies to build theory around FPF, a broader explanatory quantitative or mixed-method study would be beneficial to test the theory and to provide findings that would be generalizable to the broader industry.

\section{Acknowledgments}

The researchers would like to thank all the participants for their time and insights, and would like to thank the anonymous reviewers' feedback for helping strengthen this paper. We would also like to thank Michael Gill for constructive feedback on the methodology section, Lucia Healy for assistance with transcriptions of interviews, colleagues in TU Dublin for their careful proofreading and comments, and Dr. Henry Heberle for his assistance with the Venn diagram.

\section{ORCID}

Máirtín Mac Con Iomaire (D) http://orcid.org/0000-0001-6622-3299

Mohamed Fawzi Afifi (D) http://orcid.org/0000-0003-3083-5546

JJ Healy (D) http://orcid.org/0000-0001-6284-8750 


\section{References}

Aguinis, H., \& Solarino, A. M. (2019). Transparency and replicability in qualitative research: The case of interviews with elite informants. Strategic Management Journal, 40, 1291-1315. https://doi.org/10.1002/smj.3015

Albors-Garrigos, J., Haddaji, M., \& Garcia-Segovia, P. (2020). Gender discrimination in haute cuisine: A systematic literature and media analysis. International Journal of Hospitality Management, 89, 102569. https://doi.org/10.1016/j.ijhm.2020.102569

Allen, H., \& Mac Con Iomaire, M. (2016). 'Against all odds': Head chefs profiled. Journal of Culinary Science and Technology, 14(2), 107-135. https://doi.org/10.1080/15428052.2015. 1080645

Allen, H., \& Mac Con Iomaire, M. (2017). Secrets of a head chef: Exploring factors influencing success in Irish kitchens. Journal of Culinary Science \& Technology, 15(3), 187-222. https:// doi.org/10.1080/15428052.2016.1225538

Andaleeb, S. S., \& Conway, C. (2006). Customer satisfaction in the restaurant industry: An examination of the transaction-specific model. Journal of Services Marketing, 20(1), 3-11. https://doi.org/10.1108/08876040610646536

Auty, S. (1992). Consumer choice and segmentation in the restaurant industry. The Service Industries Journal, 12(3), 324-339. https://doi.org/10.1080/02642069200000042

Balazs, K. (2002). Take one entrepreneur: The recipe for success of France's great chefs. European Management Journal, 20(3), 247-259. https://doi.org/10.1016/S0263-2373(02) 00040-3

Bandura, A. (1977). Self-efficacy: Towards a unifying theory of behavioral change. Psychological Review, 84(2), 191-215. https://doi.org/10.1037/0033-295X.84.2.191

Bilghian, A., Peng, C., \& Kandampully, J. (2014). Generation Y's dining information seeking and sharing behavior on social networking sites. International Journal of Contemporary Hospitality Management, 26(3), 349-366. https://doi.org/10.1108/IJCHM-11-2012-0220

Birdir, K., \& Canakci, S. D. (2014). Managerial problems confronted by executive chefs in hotels. International Review of Management and Marketing, 4(3), 207-216. https://www. econjournals.com/index.php/irmm/article/view/828/pdf

Bitner, M. J., Booms, B. H., \& Mohr, L. A. (1994). Critical service encounters: The employee's viewpoint. Journal of Marketing, 58(4), 95-106. https://doi.org/10.1177/ 002224299405800408

Borchgrevink, C. P., Nelson, R. H., \& Ruf, J. L. (1998). It is a chef s life. Journal of Hospitality \& Tourism Education, 10(2), 13-18. https://doi.org/10.1080/10963758.1998.10685179

Bourdieu, P. (1984). Distinction: A social critique of the judgement of taste. (R. Nice, Trans). Harvard University Press.

Bourdieu, P. (1990). In other words: Essays towards a reflexive sociology. Polity Press.

Braun, V., \& Clarke, V. (2006). Using thematic analysis in psychology. Qualitative Research in Psychology, 3(2), 77-101. https://doi.org/10.1191/1478088706qp063oa

Brodsky-Porges, E. (1978). Organolepsis: A tool for the management of more complete eating pleasure. Journal of Food Distribution Research, 9(3), 39-42. https://doi.org/10.22004/ag. econ. 27766

Cameron, D. (2001). Chefs and occupational culture in a hotel chain: A grid-group analysis. Tourism and Hospitality Research, 3(2), 103-114. https://doi.org/10.1177/ 146735840100300202

Canziani, B. F., Almanza, B., Frash, R. E., McKeig, M. J., \& Sullivan-Reid, C. (2016). Classifying restaurants to improve usability of restaurant research. International Journal of Contemporary Hospitality Management, 28(7), 1467-1483. https://doi.org/10.1108/ IJCHM-12-2014-0618 
Chan, W. L., Hassan, W. M. W., \& Boo, H. C. (2014). The product-related failures in restaurants. Procedia - Social and Behavioral Sciences, 144, 223-228. https://doi.org/10. 1016/j.sbspro.2014.07.314

Chivers, T. S. (1972). Chefs and cooks: A study in the sociology of occupations [Unpublished PhD thesis]. University of London.

Chung, B. G., \& Hoffman, K. D. (1998). Critical incidents: Service failures that matter most. The Cornell Hotel and Restaurant Administration Quarterly, 39(3), 66-71. https://doi.org/10. $1177 / 001088049803900313$

Cimimin, M. (2011). Cooking up success. Lodging Magazine, April, 32-36.

Clark, M. A., \& Wood, R. C. (1998). Consumer loyalty in the restaurant industry: A preliminary exploration of the issues. International Journal of Contemporary Hospitality Management, 10 (4), 139-144. https://doi.org/10.1108/09596119810222104

Cohen, J. (1960). A coefficient of agreement for nominal scales. Educational and Psychological Measurement, 20(1), 37-46. https://doi.org/10.1177/001316446002000104

Cooper, J., Giousmpasoglou, C., \& Marinakou, E. (2017). Occupational identity and culture: The case of michelin-starred chefs. International Journal of Contemporary Hospitality Management, 29(5), 1362-1379. https://doi.org/10.1108/IJCHM-02-2016-0071

Cousins, J., Foskett, D., \& Gillespie, C. (2002). Food and beverage management (2nd ed.). Prentice Hall.

Cousins, J., O’Gorman, K., \& Stierand, M. (2010). Molecular gastronomy: Cuisine innovation or modern day alchemy? International Journal of Contemporary Hospitality Management, 22 (3), 399-415. https://doi.org/10.1108/09596111011035972

Csikszentmihalyi, M. (2008). Flow: The psychology of optimal experience. Harper Perennial.

De Certeau, M. (1984). The practice of everyday life. University of California Press.

Denzin, N. K., \& Lincoln, Y. S. (Eds). (2000). Handbook of qualitative research. SAGE Publications.

DiPietro, R. B., Crews, T. B., Gustafson, C., \& Strick, S. (2012). The use of social networking sites in the restaurant industry: Best practices. Journal of Foodservice Business Research, 15 (3), 265-284. https://doi.org/10.1080/15378020.2012.706193

DiPietro, R. B., Gregory, S., \& Jackson, A. (2013). Going green in quick-service restaurants: Customer perceptions and intentions. International Journal of Hospitality \& Tourism Administration, 14(2), 139-156. https://doi.org/10.1080/15256480.2013.782217

Doz, Y. (2011). Qualitative research for international business. Journal of International Business Studies, 42(5), 582-590. https://doi.org/10.1057/jibs.2011.18

Eburne, J. P. (2010). The chef drive: Cooking beyond the pleasure principle. Contemporary French and Francophone Studies, 14(2), 169-177. https://doi.org/10.1080/ 17409291003644909

Eikeland, O. (2012). Action research-applied research, intervention research, collaborative research, practitioner research, or praxis research? International Journal of Action Research, 8(1), 9-44. https://doi.org/10.1688/1861-9916_IJAR_2012_01_Eikeland

Fantasia, R. (2018). French gastronomy and the magic of Americanism. Temple University Press.

Farrington, T., Jiju, A., \& O'Gorman, K. D. (2018). Continuous improvement methodologies and practices in hospitality and tourism. International Journal of Contemporary Hospitality Management, 30(1), 581-600. https://doi.org/10.1108/IJCHM-03-2017-0141

Feinstein, A. H., \& Stefanelli, J. M. (2012). Purchasing: Selection and procurement for the hospitality industry (8th ed.). John Wiley \& Sons.

Ferguson, P. P. (1998). A cultural field in the making: Gastronomy in 19th century France. American Journal of Sociology, 104(3), 597-641. https://doi.org/10.1086/210082 
Filimonau, V., Todorova, E., Mzembe, A., Sauer, L., \& Yankholmes, A. (2020). A comparative study of food waste management in full service restaurants of the United Kingdom and the Netherlands. Journal of Cleaner Production, 258(June), 120775. https://doi.org/10.1016/j. jclepro.2020.120775

Fine, G. A. (1996). Justifying work: Occupational rhetorics as resources in restaurant kitchens. Administrative Science Quarterly, 41(1), 90-115. https://doi.org/10.2307/2393987

Foucault, M. (1977). Discipline and punish: The birth of the prison. (A. Sheridan, Trans). Vintage.

Frese, M., \& Keith, N. (2015). Action errors, error management, and learning in organizations. Annual Review of Psychology, 66(1), 661-687. https://doi.org/10.1146/annurev-psych $-010814-015205$

Gadelrab, R. M. A. (2010). Managing food quality in hotels: Integrated quality approaches to food production [Unpublished PhD Thesis]. University of Wales: Cardiff School of Management.

Giddens, A. (1984). The constitution of society. University of California Press.

Gill, M. J. (2014). The possibilities of phenomenology for organizational research. Organizational Research Methods, 17(2), 118-137. https://doi.org/10.1177/ 1094428113518348

Gill, M. J., \& Burrow, R. (2018). The function of fear in institutional maintenance: Feeling frightened as an essential ingredient in haute cuisine. Organization Studies, 39(4), 445-465. https://doi.org/10.1177/0170840617709306

Giousmpasoglou, C., Marinakou, E., \& Cooper, J. (2018). 'Banter, bollockings \& beatings': The occupational socialisation process in michelin-starred kitchen brigades in Great Britain and Ireland. International Journal of Contemporary Hospitality Management, 30(3), 1882-1902. https://doi.org/10.1108/IJCHM-01-2017-0030

Guchait, P., Neal, J. A., \& Simons, T. (2016). Reducing food safety errors in the United States: Leader behavioral integrity for food safety, error reporting, and error management. International Journal of Hospitality Management, 59, 11-18. https://doi.org/10.1016/j.ijhm. 2016.08.008

Guchait, P., Qin, Y., Madera, J., Hua, N., \& Wang, X. (2018). Impact of error management culture on organizational performance, management-team performance and creativity in the hospitality industry. International Journal of Hospitality \& Tourism Administration, 1-28. https://doi.org/10.1080/15256480.2018.1478357

Gupta, S., McLaughlin, E., \& Gomez, M. (2007). Guest satisfaction and restaurant performance. Cornell Hotel and Restaurant Administration Quarterly, 48(3), 284-298. https://doi.org/10. 1177/0010880407301735

Gustafsson, I.-B., Öström, Å., Johansson, J., \& Mossberg, L. (2006). The five aspects meal model: A tool for developing meal services in restaurants. Journal of Foodservice, 17(2), 84-93. https://doi.org/10.1111/j.1745-4506.2006.00023.x

Harris, D. A., \& Giuffre, P. (2015). Taking the heat: Women chefs and gender inequality in the professional kitchen. Rutgers University Press.

Healy, J. J., \& Mac Con Iomaire, M. (2019). Calculating restaurant failure rates using longitudinal census data. Journal of Culinary Science \& Technology, 17(4), 350-372. https://doi. org/10.1080/15428052.2018.1459999

Heberle, H., Meirelles, G. V., da Silva, F. R., Telles, G. P., \& Minghim, R. (2015). InteractiVenn: A web-based tool for the analysis of sets through Venn diagrams. BMC Bioinformatics, 16(1), 1-7. https://doi.org/10.1186/s12859-015-0611-3

Hegarty, J. A. (2008). What is the role of the chef in contemporary society? Journal of Culinary Science \& Technology, 6(1), 1-4. https://doi.org/10.1080/15428050701884113

Heidegger, M. (1962). Being and time. SCM Press. 
Hofmann, D. A., \& Frese, M. (Eds.). (2011). Error in organizations. Routledge.

Horng, J. S., \& Hu, M. L. (2008). The mystery in the kitchen: Culinary creativity. Creativity Research Journal, 20(2), 221-230. https://doi.org/10.1080/10400410802060166

Jackson, C., Vaughan, D. R., \& Brown, L. (2018). Discovering lived experiences through descriptive phenomenology. International Journal of Contemporary Hospitality Management, 30(11), 3309-3325. https://doi.org/10.1108/IJCHM-10-2017-0707

James, S. (2006). Learning to cook: Production learning environment in kitchens. Learning Environments Research, 9(1), 1-22. https://doi.org/10.1007/s10984-005-9001-5

Jones, P., \& Lockwood, A. (2004). The management of hotel operations. Thomson Learning.

Kalogeropoulos, T., Leopoulos, V., Kirytopoulos, K., \& Ventoura, Z. (2020). Project-as-practice : Applying Bourdieu's theory of practice on project managers. Project Management Journal, 1-18. https://doi.org/10.1177/8756972820913392

Kara, D., Uysal, M., Sirgy, M. J., \& Lee, G. (2013). The effects of leadership style on employee well-being in hospitality. International Journal of Hospitality Management, 34(1), 9-18. https://doi.org/10.1016/j.ijhm.2013.02.001

Katsigris, C., \& Thomas, C. (2009). Design and equipment for restaurants and foodservice. Wiley.

Kirillova, K. (2018). Phenomenology for hospitality: Theoretical premises and practical applications. International Journal of Contemporary Hospitality Management, 30(11), 3326-3345. https://doi.org/10.1108/IJCHM-11-2017-0712

Kivela, J. (1994). Menu planning. Hospitality Press.

Kivela, J., Inbakaran, R., \& Reece, J. (1999). Consumer research in the restaurant environment, Part 1: A conceptual model of dining satisfaction and return patronage. International Journal of Contemporary Hospitality Management, 11(5), 205-222. https://doi.org/10.1108/ 09596119910272739

Landis, J. R., \& Koch, G. G. (1977). An application of hierarchical kappa-type statistics in the assessment of majority agreement among multiple observers. Biometrics, 33(2), 363-374. https://doi.org/10.2307/2529786

Lee, J.-E., Almanza, B. A., Nelson, D. C., Ghiselli, R. F., \& Ghiselli, R. F. (2013). Does transformational leadership style influence employees' attitudes toward food safety practices? International Journal of Hospitality Management, 33(1), 282-293. https://doi.org/10. 1016/j.ijhm.2012.09.004

Lepkowska-White, E., \& Parsons, A. (2019). Strategies for monitoring social media for small restaurants. Journal of Foodservice Business Research, 22(4), 351-374. https://doi.org/10. 1080/15378020.2019.1626207

Lewis, B. R., \& McCann, P. (2004). Service failure and recovery: Evidence from the hotel industry. International Journal of Contemporary Hospitality Management, 16(1), 6-17. https://doi.org/10.1108/09596110410516516

Longart, P. (2010). What derives word-of-mouth in restaurant? International Journal of Contemporary Hospitality Management, 22(1), 121-128. https://doi.org/10.1108/ 09596111011013516

Loo, P. T., Boo, H. C., \& Khoo-Lattimore, C. (2013). Profiling service failure and customer online complaint motives in the case of single failure and double deviation. Journal of Hospitality Marketing \& Management, 22(7), 728-751. https://doi.org/10.1080/19368623. 2013.724373

Mac Con Iomaire, M. (2008). Understanding the heat-mentoring: A model for nurturing culinary talent. Journal of Culinary Science \& Technology, 6(1), 43-62. https://doi.org/10. $1080 / 15428050701884196$ 
Mac Con Iomaire, M. (2015). Haute cuisine restaurants in nineteenth and twentieth century Ireland. Proceedings of the Royal Irish Academy, 115C, 371-403. https://doi.org/10.3318/ PRIAC.2015.115.06

Mac Con Iomaire, M., \& O’Gorman, K. (2013). Public dining in Dublin: The history and evolution of gastronomy and commercial dining 1700-1900. International Journal of Contemporary Hospitality Management, 25(2), 227-246. https://doi.org/10.1108/09596111311301612

Mars, G., \& Nicod, M. (1984). The world of waiters. George Allen and Unwin.

May, T. (1999). Reflexivity and sociological practice. Sociological Research Online, 4(3), 1-9. https://doi.org/10.5153/sro.327

Meloury, J., \& Signal, T. (2014). When the plate is full: Aggression among chefs. International Journal of Hospitality Management, 41, 97-103. https://doi.org/10.1016/j.ijhm.2014.05.006

Mennell, S. (1996). All manners of food (2nd ed.). University of Chicago Press.

Meyer, D. (2008). Setting the table: The transforming power of hospitality in business. Harper Perennial.

Middleton, G. (2000). A preliminary study of chefs' attitudes and knowledge of healthy eating in Edinburgh's restaurants. International Journal of Hospitality Management, 19(4), 399-412. https://doi.org/10.1016/S0278-4319(00)00018-9

Murphy, J., \& Smith, S. (2009). Chefs and suppliers: An exploratory look at supply chain issues in an upscale restaurant alliance. International Journal of Hospitality Management, 28(2), 212-220. https://doi.org/10.1016/j.ijhm.2008.07.003

Murray-Gibbons, R., \& Gibbons, C. (2007). Occupational stress in the chef profession. International Journal of Contemporary Hospitality Management, 19(1), 32-42. https://doi. org/10.1108/09596110710724143

Naccarato, P., \& Lebesco, K. (2012). Culinary capital. Berg.

Namkung, Y., \& Jang, S. (2007). Does food quality really matter in restaurants? Its impact on customer satisfaction and behavioral intentions. Journal of Hospitality \& Tourism Research, 31(3), 387-410. https://doi.org/10.1177/1096348007299924

Namkung, Y., \& Jang, S. (2008). Are highly satisfied restaurant customers really different? A quality perception perspective. International Journal of Contemporary Hospitality Management, 20(2), 142-155. https://doi.org/10.1108/09596110810852131

Namkung, Y., \& Jang, S. (2010). Service failures in restaurants: Which stage of service failure is the most critical? Cornell Hospitality Quarterly, 51(3), 323-343. https://doi.org/10.1177/ 1938965510364488

Oh, H. (2000). Diners' perceptions of quality, value, and satisfaction: A practical viewpoint. The Cornell Hotel and Restaurant Administration Quarterly, 41(3), 58-66. https://doi.org/10. 1177/001088040004100317

Okumus, B. (2020). How do hotels manage food waste? Evidence from hotels in Orlando, Florida. Journal of Hospitality Marketing and Management, 29(30), 291-309. https://oi.org/ 10.1080/19368623.2019.1618775

Ortner, S. (1984). Theory in anthropology since the sixties. Comparative Study of Society and History, 16(1), 126-166. https://doi.org/10.1017/S0010417500010811

Ozdemir, B., Caliskan, O., \& Yilmaz, G. (2015). A qualitative study on process aspects of complaining in restaurants. Journal of Culinary Science \& Technology, 13(4), 330-361. https://doi.org/10.1080/15428052.2015.1058204

Pantelidis, I. S. (2010). Electronic meal experience: A content analysis of online restaurant comments. Cornell Hospitality Quarterly, 51(4), 483-491. https://doi.org/10.1177/ 1938965510378574

Parsa, H. G., Self, J. T., Njite, D., \& King, T. (2005). Why restaurants fail. Cornell Hotel and Restaurant Administration Quarterly, 46(3), 304-322. https://doi.org/10.1177/ 0010880405275598 
Parsa, H. G., Shuster, B. K., \& Bujisic, M. (2020). New classification system for the U.S. restaurant industry: Application of utilitarian and hedonic continuum model. Cornell Hospitality Quarterly, 61(4), 379-400. https://doi.org/10.1177/193896551989992

Partlow, C. G. (1993). How Ritz-Carlton applies “TQM”. Cornell Hospitality Quarterly, 34(4), $16-24$.

Pavlov, I. P. (1927). Conditioned reflexes: An investigation of the physiological activity of the cerebral cortex. (G. V. Anrep, Trans). Oxford University Press.

Pernecky, T., \& Jamal, T. (2010). (Hermeneutic) phenomenology in tourism studies. Annals of Tourism Research, 37(4), 1055-1075. https://doi.org/10.1016/j.annals.2010.04.002

Pine, B. J., \& Gilmore, J. H. (1998). Welcome to the experience economy. Harvard Business Review, 76, 97-105. https://www.hbr.org/1998/07/welcome-to-the-experience-economy

Pratten, J. D. (2003). What makes a great chef? British Food Journal, 105(7), 454-459. https:// doi.org/10.1108/00070700310497255

Quigley, K., Connolly, M., Mahon, E., \& Mac Con Iomaire, M. (2019). Insight from insiders: A phenomenological study for exploring food tourism policy in Ireland, 2009-2019. Advances in Hospitality and Tourism Research, 7(2), 188-215. https://doi.org/10.30519/ ahtr.574519

Raajpoot, N. A. (2002). TANGSERV: A multiple item scale for measuring tangible quality in foodservice industry. Journal of Foodservice Business Research, 5(2), 109-127. https://doi. org/10.1300/J369v05n02_08

Ramdeen, C., Santos, J., \& Chatfield, H. K. (2007). Measuring the cost of quality in a hotel restaurant operation. International Journal of Contemporary Hospitality Management, 19(4), 286-295. https://doi.org/10.1108/09596110710747625

Reason, J. (2000). Human error: Models and management. BMJ, 320(7237), 768-770. https:// doi.org/10.1136/bmj.320.7237.768

Reiter, E. (1996). Making fast food: From the frying pan into the fryer. McGill-Queen's University Press.

Robinson, R. N. S., \& Barron, P. E. (2007). Developing a framework for understanding the impact of deskilling and standardisation on the turnover and attrition of chefs. International Journal of Hospitality Management, 26(4), 913-926. https://doi.org/10.1016/j.ijhm.2006.10. 002

Robinson, R. N. S., Solnet, D. J., \& Breakey, N. (2014). A phenomenological approach to hospitality management research: Chefs' occupational commitment. International Journal of Hospitality Management, 43, 65-75. https://doi.org/10.1016/j.ijhm.2014.08.004

Rodgers, S. (2008). Technological innovation supporting different food production philosophies in the food service sectors. International Journal of Contemporary Hospitality Management, 20(1), 19-34. https://doi.org/10.1108/09596110810848541

Rozin, E. (1982). The structure of cuisine. In L. M. Barker (Ed.), The psychobiology of human food selection (pp. 189-203). AVI.

Salameh, M., \& Barrows, C. W. (2001). The role of training in achieving TQM in restaurants. Journal of Quality Assurance in Hospitality \& Tourism, 1(4), 73-95. https://doi.org/10.1300/ J162v01n04_05

Schatzki, T. (2018). On practice theory, or what's practices got to do (got to do) with it? In C. Edwards-Groves. (Ed.), Education in an Era of Schooling (pp. 151-165). Springer. https:// doi.org/10.1007/978-981-13-2053-8_11.

Self, J. T., Jones, M. F., \& Botieff, M. (2015). Where restaurants fail: A longitudinal study of micro locations. Journal of Foodservice Business Research, 18(4), 328-340. https://doi.org/10. 1080/15378020.2015.1068670 
Silber, I., Israeli, A., Bustin, A., \& Ben Zvi, O. (2009). Recovery strategies for service failures: The case of restaurants. Journal of Hospitality Marketing \& Management, 18(7), 730-740. https://doi.org/10.1080/19368620903170273

Silvennoinen, K., Heikkilä, L., Katajajuuri, J.-M., \& Reinikainen, A. (2015). Food waste volume and origin: Case studies in the Finnish food service sector. Waste Management, 46, 140-145. https://doi.org/10.1016/j.wasman.2015.09.010

Smith, J. A. (1996). Beyond the divide between cognition and discourse: Using interpretative phenomenological analysis in health psychology. Psychology \& Health, 11(2), 261-271. https://doi.org/10.1080/08870449608400256

Spence, C. (2018). Gastrophysics: The new science of eating. Penguin.

Stierand, M., Dörfler, V., \& Sharma, A. (2012). Reflecting on a phenomenological study of creativity and innovation in haute cuisine. International Journal of Contemporary Hospitality Management, 24(6), 946-957. https://doi.org/10.1108/09596111211247254

Sulek, J. M., \& Hensley, R. L. (2004). The relative importance of food, atmosphere, and fairness of wait: The case of a full-service restaurant. Cornell Hotel and Restaurant Administration Quarterly, 45(3), 235-247. https://doi.org/10.1177/0010880404265345

Susskind, A. M. (2002). I told you so! Restaurant customers' word-of-mouth communication patterns. Cornell Hotel and Restaurant Administration Quarterly, 43(2), 75-85. https://doi. org/10.1177/001088040204300208

Susskind, A. M., \& Chan, E. K. (2000). How restaurant features affect check averages. Cornell Hotel and Restaurant Administration Quarterly, 41(6), 56-63. https://doi.org/10.1177/ 001088040004100608

Taylor, E., \& Taylor, J. (2008). A new method of HACCP for hospitality: From concept to product. International Journal of Contemporary Hospitality Management, 20(5), 524-541. https://doi.org/10.1108/09596110810881454

Taylor, J., \& Forte, J. (2008). HACCP for hospitality industry: The chef's perspective. International Journal of Contemporary Hospitality Management, 20(5), 494-507. https:// doi.org/10.1108/09596110810881436

Taylor, J. Z. (2008). HACCP for hospitality industry: A psychological model for success. International Journal of Contemporary Hospitality Management, 20(5), 508-523. https:// doi.org/10.1108/09596110810881445

Walsh, C., \& Leva, M. C. (2019). A review of human factors and food safety in Ireland. Safety Science, 119, 399-411. https://doi.org/10.1016/j.ssci.2018.07.022

Wan, T-H., Hsu, Y.S., Wong, J.Y., and Liu, S.H. (2017) Sustainable international tourist hotels: the role of the executive chef. International Journal of Contemporary Hospitality Management 29(7), 1873-1891. https://doi.org/10.1108/IJCHM-08-2015-0406

Wang, X., Guchait, P., \& Pasamehmetoglu, A. (2020). Anxiety and gratitude toward the organization: Relationships with error management culture and service recovery performance. International Journal of Hospitality Management, 89, 102592. https://doi. org/10.1016/j.ijhm.2020.102592

Wellton, L., Jonsson, I. M., \& Svingstedt, A. (2019). 'Just trained to be a chef, not a leader': A study of head chef practices. International Journal of Hospitality \& Tourism Administration, 20(4), 400-422. https://doi.org/10.1080/15256480.2017.1397584

Whyte, W. F. (1948). Human relations in the restaurant industry. McGraw-Hill.

Wittgenstein, L. (1957). Philosophical investigations (G. E. M. Anscombe, Trans). (3rd ed.). Macmillan.

Wyckoff, D. D. (1984). New tools for achieving service quality. Cornell Hotel and Restaurant Administration Quarterly, 25(3), 78-91. https://doi.org/10.1177/001088048402500317

Yao, S., Wang, X., Yu, H., \& Guchait, P. (2019). Effectiveness of error management training in the hospitality industry: Impact on perceived fairness and service recovery performance. 
International Journal of Hospitality Management, 79, 78-88. https://doi.org/10.1016/j.ijhm. 2018.12.009

Yilmaz, Ö. D. (2018). Revisiting employee-guest interactions in hotels: An analysis of critical incidents. Journal of Tourism, Heritage \& Services Marketing, 4(2), 17-23. https://doi.org/10. 5281/zenodo.1490400

Zetie, S., Sparrow, J., Woodfield, A., \& Kilmartin, T. (1994). The tyrannical chef: A barrier to TQM? International Journal of Contemporary Hospitality Management, 6(1/2), 42-45. https://doi.org/10.1108/09596119410052116

Zhao, H., \& Guo, L. (2019). Abusive supervision and hospitality employees' helping behaviors: The joint moderating effects of proactive personality and ability to manage resources. International Journal of Contemporary Hospitality Management, 31(4), 1977-1994. https:// doi.org/10.1108/IJCHM-01-2018-0100

Zopiatis, A. (2010). Is it art or science? Chef s competencies for success. International Journal of Hospitality Management, 29(3), 459-467. https://doi.org/10.1016/j.ijhm.2009.12.003

Zopiatis, A., Kyprianou, G., \& Pavlou, I. (2011). Occupational challenges facing chefs: The case of Cyprus. Journal of Quality Assurance in Hospitality \& Tourism, 12(2), 104-120. https:// doi.org/10.1080/1528008X.2011.541822

\section{Appendix A}

Cohen's Kappa was calculated using the formula:

$\mathrm{p}-\mathrm{e}(\mathrm{K}) 1-\mathrm{e}(\mathrm{K}) p$-eK1-eK

Where $\mathrm{p}$ is the overall percent agreement $(\mathrm{p})=\mathrm{A}+\mathrm{DNp}=\mathrm{A}+\mathrm{DN}$

$A=$ the number of times both raters classify a subject into category 1

$D=$ the number of times both raters classify a subject into category 2

$N=$ the total sample size

$e(K)=$ the chance agreement probability $=\left(\mathrm{A} 1 \mathrm{~N}^{\star} \mathrm{B} 1 \mathrm{~N}\right)+\left(\mathrm{A} 2 \mathrm{~N}^{\star} \mathrm{B} 2 \mathrm{~N}\right)$ 